\title{
Recent Trends in Temperature and Precipitation in the Langat River Basin, Malaysia
}

\author{
Mahdi Amirabadizadeh, ${ }^{1}$ Yuk Feng Huang, ${ }^{2}$ and Teang Shui Lee ${ }^{1}$ \\ ${ }^{1}$ Faculty of Engineering, Universiti Putra Malaysia, 43300 Serdang, Selangor, Malaysia \\ ${ }^{2}$ Faculty of Engineering and Science, Universiti Tunku Abdul Rahman, 53300 Kuala Lumpur, Malaysia \\ Correspondence should be addressed to Mahdi Amirabadizadeh; mamir692@gmail.com
}

Received 10 September 2014; Revised 7 November 2014; Accepted 20 November 2014

Academic Editor: Lin Wang

Copyright (c) 2015 Mahdi Amirabadizadeh et al. This is an open access article distributed under the Creative Commons Attribution License, which permits unrestricted use, distribution, and reproduction in any medium, provided the original work is properly cited.

\begin{abstract}
A study was undertaken to detect long-term trends in the annual and seasonal series of maximum and minimum temperatures. Measurements were taken at 11 meteorological stations located in the Langat River Basin in Malaysia. The rainfall and maximum and minimum temperature data were obtained from the Malaysia Meteorological Department (MMD) and the Department of Irrigation and Drainage (DID) Malaysia. The procedures used included the Mann-Kendall test, the Mann-Kendall rank statistic test, and the Theil-Sen's slope method. The analytical results indicated that when there were increasing and decreasing trends in the annual and seasonal precipitation and temperature, only the increasing trends were significant at the $95 \%$ confidence level. The Theil-Sen's slope method showed that the rate of increment in the annual precipitation is greater than the seasonal precipitation. A bootstrap technique was applied to explore uncertainty about significant slope values for rainfall, as well as the maximum and minimum temperatures. The Mann-Kendall rank statistics test indicated that most of the trends in the annual and seasonal time series started in the year 2000. All of the annual and seasonal significant trends were obtained at the stations located in the north, east, and northeast portions of the Langat River Basin.
\end{abstract}

\section{Introduction}

Quantitatively speaking, climate change refers to the statistically significant variations of the mean state of the climate or that of its variability for decades or even over a longer period [1]. Although climate change happens globally, its effects, however, can be deterministic, dependent on the region of study. Temperature and precipitation variables are the most important measures that indicate the signs of climate change. The Intergovernmental Panel on Climate Change (IPCC) AR4 specified that the average global surface temperature has increased by $0.074^{\circ} \mathrm{C}$ per year from 1906 to 2000 [2]. Furthermore, the IPCC AR5 report indicated that increases in mean temperature will continue for the 2016-2035 period [1]. The reports from IPCC also indicated that the frequency of extreme rainfall events have increased over most land areas, consistent with growing temperatures and atmospheric water vapour [3]. An analysis of the long-term changes in climate variables is very crucial for water resource planning and management, as well as to put things into their proper perspective and context [4].

Many trend analyses have been carried out on climate variables, especially with temperature and precipitation. Many of researchers applied the nonparametric MannKendall method in the detection of trend in hydrologic variables $[5,6]$. The Mann-Kendall rank statistics test and Theil-Sen's slope method are other methods that are widely used to declare trends and magnitude changes in the climate variables in annual and seasonal time scales $[7,8]$.

The comparison between the trend detection methods is the main subject of many studies. Yue et al. [9] compared the power of the Mann-Kendall and Spearman tests for detecting the monotonic trend in time series. They stated that the power of the test depends on the slope of trend, level of significance, sample size, and properties of the datasets, such as skewness and variation. The test results also demonstrated that both of the tests provided the same consequences in the absence of autocorrelation. 


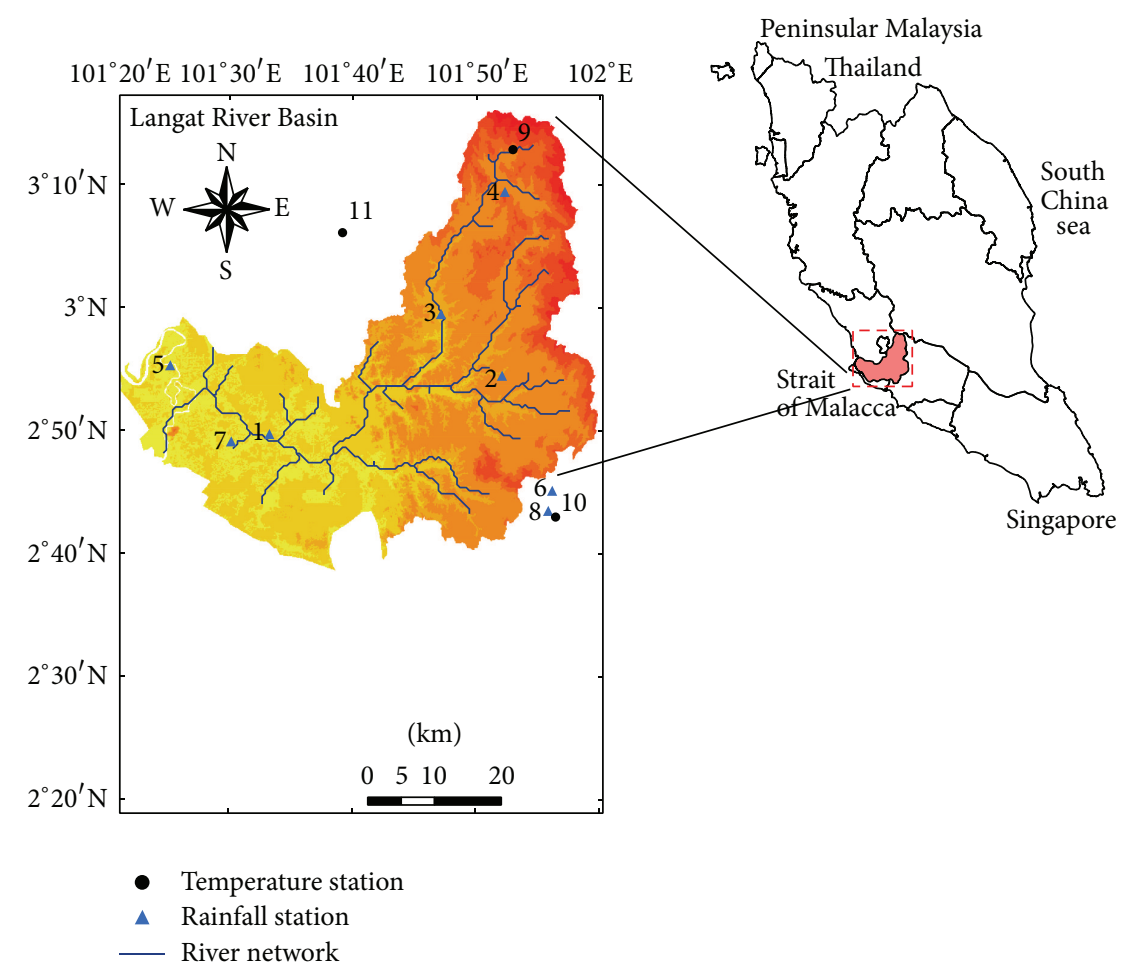

FIGURE 1: Geographic location and spatial distribution of stations in the Langat River Basin.

While there were interests in the examination of the existence of trends for many climatic variables in Malaysia, a limited number of studies have been done in this country. Meng et al. [10] investigated the trend of regional warming in Malaysia using a mean annual temperature time series of approximately 50 years. Their findings showed complete agreement with the temperature increments reported by the IPCC for Malaysia, which are 0.99 to $3.44^{\circ} \mathrm{C}$ per 100 years. Tangang et al. [11] applied the Mann-Kendall test for 32 stations over whole peninsula of Malaysia for the period of 1974-2004. The MK test for mean, variability, and persistence of wet spells revealed positive and negative trends in the stations east of the peninsula during the northeast monsoon and southwest monsoon seasons, respectively. They also concluded that there is a wide gap in the knowledge of climate change throughout Malaysia.

Suhaila et al. [12] investigated the existing trends in daily rainfall in peninsular Malaysia based on seasonal rainfall during 1975-2004. The results of the Mann-Kendall test indicated a decreasing trend in the total amount of rainfall and frequency of wet days, as well as the increasing trend in rainfall intensity during the southwest monsoon. On the contrary, the results of the test showed reverse trends in the parameters for northeast monsoon flow.

The comparison associated with preceding studies in climate change in Malaysia indicated that there is a gap in many climate parameters such as maximum temperature, minimum temperature, and annual precipitation-one of the most important factor. Furthermore the beginning of trend is actually another concern that was not addressed in the past researches.
In this study, we analysed and examined the signs of change in the annual precipitation, as well as the maximum and minimum temperature regime, specific to Langat River Basin (a strategic basin), located in Malaysia (Figure 1). The Langat River Basin is the most urbanised river basin in Malaysia, located in the southern part of Klang Valley. During the last decade, this watershed has experienced rapid development in urbanisation, agriculture, and industrialisation. This watershed supplies water to two-thirds of the state of Selangor for its domestic, hydroelectric plant, industry, and agricultural consumption. As Selangor State is currently facing a water shortage problem, especially during the southwest monsoon season, analysing the trends of rainfall and the maximum and minimum temperatures is a vital activity in management of the water resources for the future. The objectives of this research were achieved using the MannKendall and Mann-Kendal rank statistic methods. The rates of changes in these variables were then determined using the Theil-Sen's slope method.

\section{Materials and Methods}

2.1. Study Area. The total area of the Langat River Basin is approximately $2352 \mathrm{~km}^{2}$. It lies between latitudes $2^{\circ} 40^{\prime} 15^{\prime \prime}$ to $3^{\circ} 16^{\prime} 15^{\prime \prime} \mathrm{N}$ and longitudes $101^{\circ} 17^{\prime} 20^{\prime \prime}$ to $101^{\circ} 55^{\prime} 10^{\prime \prime} \mathrm{E}$ in the southern part of the Klang Valley region. The northern part of the basin is a mountainous area, while its southern part consists of a flat area. The mean areal annual rainfall of the Langat River Basin is $1994.1 \mathrm{~mm}$. The highest recorded monthly rainfall is about $327.1 \mathrm{~mm}$, occurring in November, while the lowest is $97.6 \mathrm{~mm}$ in June. These two maximum and 
TABLE 1: Geographic characteristics of stations for recorded precipitation data.

\begin{tabular}{|c|c|c|c|c|c|}
\hline Station ID & Number & Longitude (E) & Latitude $(\mathrm{N})$ & Altitude $(\mathrm{m})$ & Period \\
\hline 2815001 & 1 & $101^{\circ} 32^{\prime}$ & $2^{\circ} 49^{\prime}$ & 3 & 1971-2011 \\
\hline 2818110 & 2 & $101^{\circ} 52^{\prime}$ & $2^{\circ} 53^{\prime}$ & 36 & 1971-2011 \\
\hline 2917001 & 3 & $101^{\circ} 47^{\prime}$ & $2^{\circ} 59^{\prime}$ & 39 & 1976-2011 \\
\hline 3118102 & 4 & $101^{\circ} 52^{\prime}$ & $3^{\circ} 10^{\prime}$ & 91 & 1971-2011 \\
\hline 2913001 & 5 & $101^{\circ} 23^{\prime}$ & $2^{\circ} 55^{\prime}$ & 3 & 1974-2011 \\
\hline 2719001 & 6 & $101^{\circ} 56^{\prime}$ & $2^{\circ} 45^{\prime}$ & 93 & 1971-2011 \\
\hline 44256 & 7 & $101^{\circ} 30^{\prime}$ & $2^{\circ} 49^{\prime}$ & 8 & $1974-2011$ \\
\hline 45241 & 8 & $101^{\circ} 56^{\prime}$ & $2^{\circ} 43^{\prime}$ & 64.1 & 1974-2011 \\
\hline Ampangan & 9 & $101^{\circ} 53^{\prime}$ & $3^{\circ} 13^{\prime}$ & 233.3 & 1985-2011 \\
\hline Hospital Seremban & 10 & $101^{\circ} 56^{\prime} 37^{\prime \prime}$ & $2^{\circ} 42^{\prime} 33^{\prime \prime}$ & 64.1 & 1971-2011 \\
\hline Petaling Jaya & 11 & $101^{\circ} 39^{\prime}$ & $3^{\circ} 6^{\prime}$ & 60.8 & 1974-2011 \\
\hline
\end{tabular}

minimum precipitations occurred in the northeast monsoon and the southwest monsoon periods, respectively.

Besides global warming, the climate of Malaysia is associated with many global and regional phenomena, such as monsoons, El Nino/La Nina, and the Indian Ocean Dipole (IOD). These phenomena could affect the severity of extreme events in the country. Scientists state that global warming will directly affect systems, such as hydrological cycles, and extreme events, such as El Nino/La Nina [13].

In the seasonal time scale, the surface climate in Malaysia is affected by two monsoon regimes, namely, the southwest (SW) monsoon and northeast (NE) monsoon patterns. The SW monsoon season that is dominated by the low level southwesterly winds begins in May and lasts through August. On the other hand, the NE monsoon season that is controlled by the northeast wind commences in November and ends in February of the following year [14].

The recorded data for rainfall (subdaily measurements) and maximum and minimum temperature (daily measurements) were obtained from the Malaysia Meteorological Department (MMD) and Department of Irrigation and Drainage (DID). The daily data for precipitation was extracted from subdaily data at each station. The series of annual and monsoon seasonal recorded data, which included the maximum temperature $\left(T_{\mathrm{Max}}\right)$, the minimum temperature $\left(T_{\text {Min }}\right)$, and total precipitation $(P)$, were analysed for the existence of monotonic trends.

The seasonal and annual values of $T_{\text {Max }}$ and $T_{\text {Min }}$ were computed as the average values over the season and year, respectively. The study periods were matched to all the available records at each station, which varied between 27 and 41 years. The recorded daily data were available at three temperature stations and eight precipitation stations. Monthly values were averaged to obtain the NE monsoon (winter) and SW monsoon (summer) temperature for each of the three stations. Spatial distribution and geographic characteristics of the precipitation and temperature stations are shown in Figure 1 and Table 1, respectively.

These stations were chosen as the database due to the good quality datasets, suitable length (close to 30 years) of data recorded, which is considered to be long enough for studying the changes in climate, and good spatiality distribution in the mountainous and flat regions to cover the whole area of the river basin.

In the analysis of climate variables, it is primarily important to investigate the quality of the recorded climatic data, such as looking for missing values, analysing the outliers, and also administering the consistency test. In the case of missing observations, the daily missed values were repaired using the Ameliaview1.1 package in $\mathrm{R}$ software [15], which is based on the bootstrap method. Also, for the longer missed observations, the recorded values in neighbouring stations that had high correlations were used to complete the temperature and precipitation time series.

Outliers in the data sets can lead to false trend results and inaccurate statistical properties [16]. Bremer [17] found that the interquartile ratio (IQR) method reduces biases in the dataset caused by outliers, while also keeping the information for extreme events as well. In the IQR method, the higher and lower thresholds are described by Q75\% $+5^{*} \mathrm{IQR}$ and Q25\% - 5* IQR, respectively [18]. Then, each value greater or smaller than the higher and lower bands, respectively, is set as an outlier and eliminated from the data sets.

The homogeneity of the time series has been investigated by many researchers [19]. In this study, the double-mass curve procedure [20] was applied to test the consistency of climate variables. The double-mass curve method is a graphical procedure to identify the inconsistency of station records by comparing the time trend in one station with other relatively stable records at other stations or the average of several nearby stations [6]. Results of the double masscurves for all of the stations are straight lines, and no apparent breakpoints are detected in the time series

The mean value of precipitation $(P)$ at the observed stations varied between 1658.3 in Station 1 and $2351.6 \mathrm{~mm}$ in Station 8, which are located in the flat and mountainous areas, respectively. This pattern was repeated for the mean of the seasonal precipitation in the SW monsoon and NE monsoon seasons. This is shown in Table 2 and Figure 2.

As shown in Figure 2, the ranges of variation at Stations 9 and 11 are the smallest and greatest values in the temperature time series, respectively. These differences in $T_{\text {Max }}$ and $T_{\text {Min }}$ between stations were more related to the land use and altitude of gauging stations. Station 9, located in forest and 
TABLE 2: Statistical properties of annual and seasonal rainfall and temperature in the Langat River Basin.

\begin{tabular}{|c|c|c|c|c|c|c|c|c|c|c|}
\hline \multirow{3}{*}{ Station } & \multirow{3}{*}{ Variable } & \multicolumn{3}{|c|}{ Annual } & \multicolumn{6}{|c|}{ Seasonal } \\
\hline & & & & & & Monsoo & & & W Monso & \\
\hline & & Mean & S.D. & Skew & Mean & S.D. & Skew & Mean & S.D. & Skew \\
\hline 1 & \multirow{8}{*}{ Precipitation } & 1658.3 & 304.9 & -0.14 & 583.5 & 182.37 & 0.03 & 468.8 & 143.64 & 0.06 \\
\hline 2 & & 1883.8 & 366.3 & 0.35 & 594.5 & 181.72 & 0.73 & 517.5 & 144.83 & 0.68 \\
\hline 3 & & 2191.2 & 417.3 & -0.31 & 773.3 & 245.15 & 0.13 & 562.8 & 175.61 & 0.15 \\
\hline 4 & & 2128.7 & 379.5 & 0.36 & 662.1 & 198.53 & -0.14 & 638.0 & 178.20 & 0.39 \\
\hline 5 & & 1750.3 & 396.6 & -0.16 & 687.9 & 219.40 & 0.45 & 460.4 & 122.03 & 0.68 \\
\hline 6 & & 1951.9 & 363.1 & 0.01 & 620.5 & 188.53 & 0.24 & 539.7 & 141.00 & 0.1 \\
\hline 7 & & 1965.6 & 470.9 & 2.43 & 677.2 & 206.92 & 1.35 & 606.7 & 188.01 & 1.45 \\
\hline 8 & & 2351.6 & 345.4 & -0.38 & 786.1 & 224.75 & -0.09 & 648.6 & 140.17 & 0.58 \\
\hline \multirow{2}{*}{9} & $T_{\text {Max }}$ & 31.7 & 0.46 & 0.07 & 31.1 & 0.62 & -0.08 & 32.0 & 0.42 & 0.67 \\
\hline & $T_{\text {Min }}$ & 21.6 & 0.47 & -0.88 & 21.5 & 0.44 & -0.79 & 21.7 & 0.50 & -1.23 \\
\hline \multirow{2}{*}{10} & $T_{\text {Max }}$ & 31.9 & 0.36 & 0.48 & 31.9 & 0.54 & 0.61 & 31.8 & 0.28 & 0.52 \\
\hline & $T_{\text {Min }}$ & 23.5 & 0.55 & -0.18 & 23.4 & 0.58 & -1.08 & 23.6 & 0.55 & -0.08 \\
\hline \multirow{2}{*}{11} & $T_{\mathrm{Max}}$ & 32.8 & 0.42 & 0.04 & 32.4 & 0.66 & 0.49 & 32.9 & 0.4 & 0.13 \\
\hline & $T_{\text {Min }}$ & 24.0 & 0.57 & 0.31 & 23.7 & 0.61 & 0.27 & 24.2 & 0.58 & 0.23 \\
\hline
\end{tabular}

mountainous regions, demonstrated less variation in the maximum and minimum temperatures than did the two other stations near the urban area and lower altitudes. The 5-year moving average indicated an approximate monotonic increasing trend for the annual maximum temperature in Station 9 and the annual minimum temperature in Stations 10 and 11.

As shown in Figure 3(b), the stations that are located north and east of the Langat River Basin receive more rainfall than do those stations west of the basin during the study period. These results are consistent with those obtained by Deni et al. [21]. The mean annual $T_{\text {Max }}$ and $T_{\text {Min }}$ range from 31.6 to $33^{\circ} \mathrm{C}$ and 21.6 to $24.2^{\circ} \mathrm{C}$ respectively.

2.2. Trend Analysis. There are two main ways to declare the significant trends in the climatic data sets: parametric and nonparametric trend methods. In the parametric trend analysis, data should be independent and normally distributed, while in the nonparametric method, the only requirement is to be independent. In this study, the nonparametric MannKendall was used for the detection of significant trends, the Mann-Kendall rank statistic test was used for determining the beginning of trend, and the Theil-Sen's slope procedure was applied to measure the quantity of change in the climatologic time series.

2.2.1. Mann-Kendal Test. The Mann-Kendall (MK) test is a robust method of detecting a monotonic trend in hydroclimate data. The MK method is a rank-based procedure, with a strength being the application in skewed data. Another suitable property of this test is that it has a low sensitivity to abrupt breaks, which may be caused by inhomogeneous data.

For an observed time series $x=x_{1}, x_{2}, x_{n}$, the trend test statistic $S$ is given by

$$
S=\sum_{i=1}^{n-1} \sum_{j=i+1}^{n} \operatorname{Sgn}\left(x_{j}-x_{i}\right),
$$

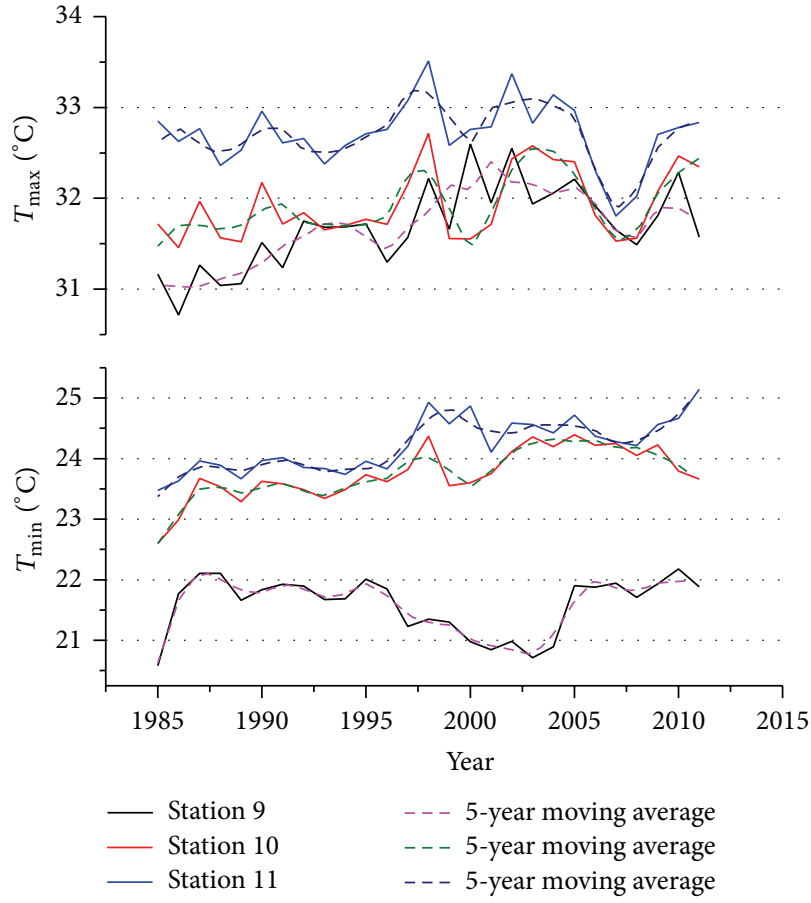

FIgURE 2: Annual maximum and minimum temperatures and their 5 -year moving average in the Langat River Basin.

where

$$
\operatorname{Sgn}(x)= \begin{cases}1, & x>0 \\ 0, & x=0 \\ -1, & x<0\end{cases}
$$

And $i$ and $j$ are the rank of observation of the $x_{i}, x_{j}$ of time series. 

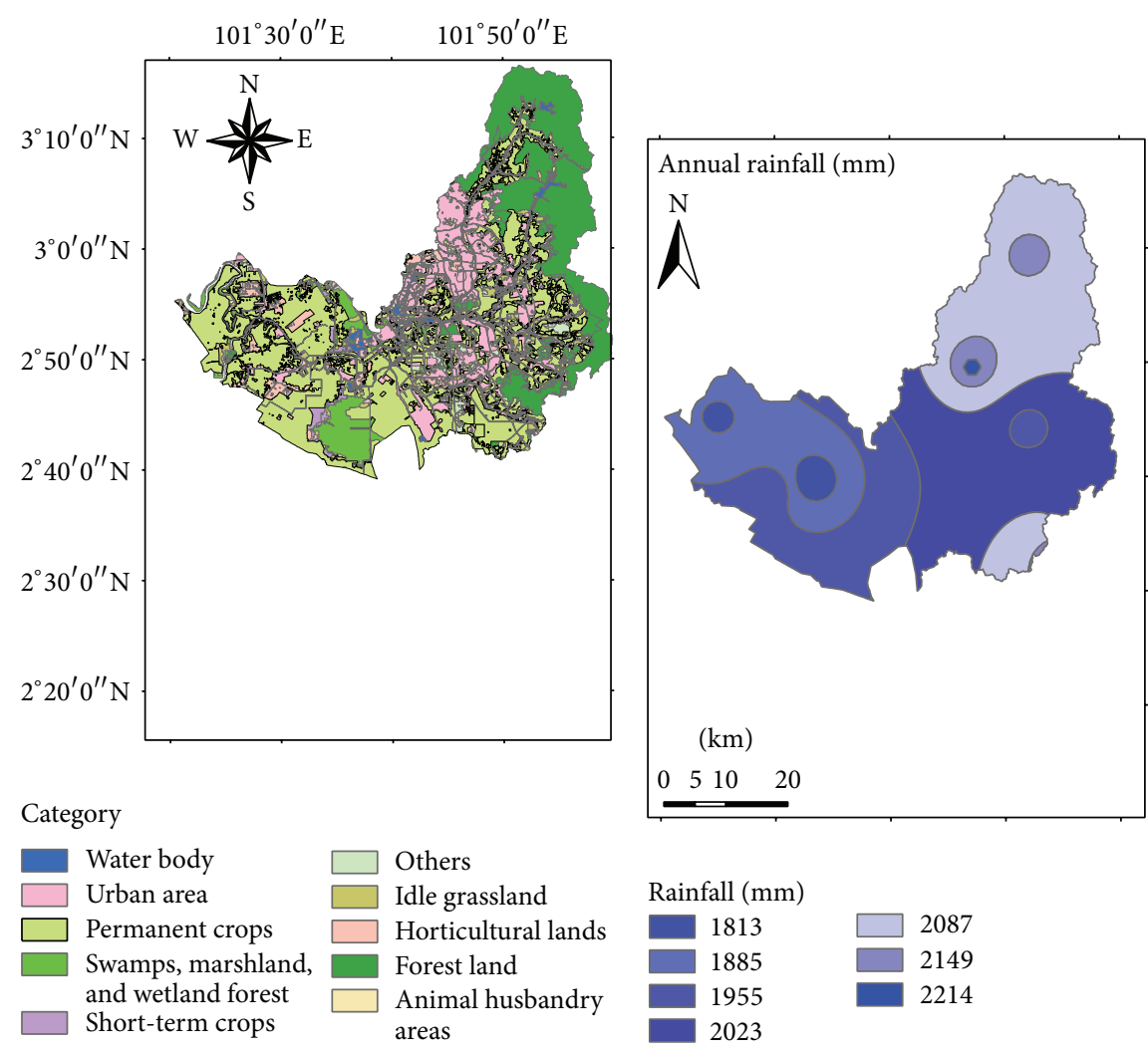

(a)

(b)
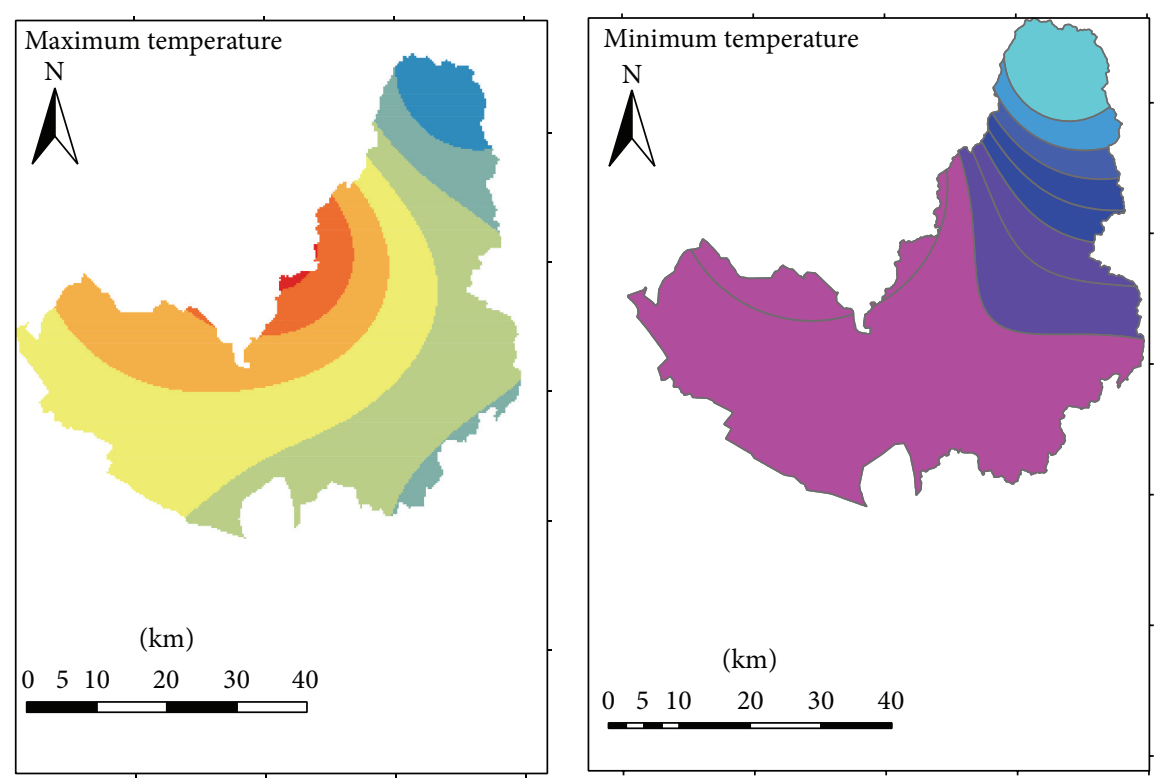

31.6-31.8

$31.8-32$

32.4-32.6

$32.0-32.2$

32.6-32.8

$32.2-32.4$

$32.8-33$

(c)

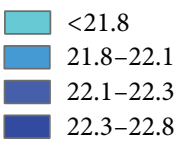

22.3-22.8

(d)

FIGURE 3: Spatial characteristics of the Langat River Basin include (a) land use map, (b) annual precipitation, (c) minimum temperature, and (d) maximum temperature. 
The variance is computed as

$$
V=\frac{n(n-1)(2 n+5)}{18}-\sum_{i=1}^{g} \frac{t_{i}\left(t_{i}-1\right)\left(2 t_{i}+5\right)}{18},
$$

where $g$ is the number of groups of tied rank and $t_{i}$ is number of ties in group $i$. For a sample size of 30 or larger, the $S$ statistic is normally distributed and the value of the standard deviation is computed by

$$
Z= \begin{cases}\frac{s-1}{V^{0.5}} & S>0 \\ 0 & S=0 \\ \frac{s+1}{V^{0.5}} & S<0\end{cases}
$$

When $|Z|>Z_{1-\alpha / 2}$ or the $P$ value is smaller than the significance level $(\alpha)$, the null hypothesis is rejected and there is a significance trend in the time series. The $Z_{1-\alpha / 2}$ and $P$ value are obtained from the standard normal distribution table. In this study, the significance level is $\alpha=0.05$ and therefore the null hypothesis of no trend is rejected while $|Z|>1.96$.

The MK test analysis technique was widely used in detecting trends in climate variables $[5,8,22-26]$. The prewhitening procedure was carried out before completing the MK test to eliminate the influence of autocorrelation on the results of the test. The prewhitening procedure is described in Section 2.3.

2.2.2. Mann-Kendall Rank Statistic Test. According to Sneyers [27], the Mann-Kendall rank statistic (MKRS) test is used to determine the approximate beginning year of significant trends (e.g., $[6,14,28]$ ). Two sequential values, $U_{t}$ and $U_{t}^{\prime}$, are determined from progressive and backward time series, respectively. This method uses relative values of each element in the time series $\left(x_{1}, x_{2}, \ldots, x_{n}\right)$. The following steps are utilised in four sequences.

(1) The magnitudes of $x_{i}$ annual or seasonal time series $(i=1, \ldots, n)$ are compared with $x_{j}(j=1, \ldots, i-1)$. At each comparison, the number of cases $x_{i}>x_{j}$ is counted and indicated by $n_{i}$.

(2) The test statistic $t_{i}$ variable is computed using

$$
t_{i}=\sum_{i=1}^{i} n_{i}
$$

(3) As the $t_{i}$ distribution is asymptotically normal, the mean and variance of $t_{i}$ are calculated as follows:

$$
\begin{gathered}
E(t)=\frac{n(n-1)}{4}, \\
\operatorname{Var}\left(t_{i}\right)=\frac{1}{72}[i(i-1)(2 j+5)] .
\end{gathered}
$$

(4) Finally, the sequential values of the $U_{t}$ are computed by

$$
U_{t}=\frac{t_{i}-E(t)}{\sqrt{\operatorname{Var}\left(t_{i}\right)}}
$$

Similarly, these four steps are followed to compute the $U_{t}^{\prime}$ in backward direction, from the end of the time series. If the time series of $U_{t}$ and $U_{t}^{\prime}$ intersect each other and at least one of them is greater than a chosen level of significance, then there is a statistically significant trend. The point where the $U_{t}$ and $U_{t}^{\prime}$ cross each other indicates the approximate beginning year of a developing trend within the time series. In this study, as the level of significance $\alpha=0.05$, then the absolute values of calculating $U_{t}$ and $U_{t}^{\prime}$ are compared with the Gaussian distribution value 1.96 .

2.2.3. Theil-Sen's Slope Method. The Theil-Sen's slope method [29] is used to estimate the rate of change the rate of change:

$$
\beta=\operatorname{Median}\left(\frac{x_{j}-x_{i}}{j-1}\right) \quad i<j,
$$

where $x_{j}$ and $x_{i}$ are the data values in times $j$ and $i$, respectively. The $\beta$ sign represents the direction of change and its value indicates the steepness of change $[7,25]$. According to Yue et al. [9], the slope estimated by Theil-Sen's slope (TSS) estimator is a robust estimation of the magnitude of the trend. In order to determine the magnitude of TSS, an algorithm in $\mathrm{R}$ programme that corresponds to an extension of original TSS test was applied. This technique is frequently used in determining the slope of trend in climate variable time series (e.g., [5, 30-33]).

2.3. Influence of Serial Correlation. In time series analysis, it is essential that the data sets used for trend analysis be free of serial correlation in the time series. von Storch and Navarra [34] found that the presence of serial correlation in the time series can complicate the results of the identification of the trend detection for the Mann-Kendall test since the positive first-order autocorrelation can increase the expected number of false positive outcomes. In this study, the trendfree prewhitening (TFPW) approach that was modified by Burn et al. [35] was used prior to the application of the Mann-Kendall and Theil-Sen's slope procedures to remove the significant serial correlation from the time series. This procedure can be followed in five steps.

(1) Compute the TSS, $\beta$, using (8).

(2) Remove the monotonic trend from the original data sets using

$$
Y_{t}=X_{t}-\beta t
$$

where $X_{t}$ is the time series value at time $t$ and $Y_{t}$ is the detrended series.

(3) Compute $r_{1}$, the lag-1 serial correlation of the new series. If the value of $r_{1}$ is not statistically significant at the $5 \%$ level, the estimated $\beta$ is accepted. Otherwise, the detrended series is prewhitened through

$$
Y_{t}^{\prime}=Y_{t}-r_{1} Y_{t-1}
$$

where $Y_{t}^{\prime}$ is the prewhitened series. 


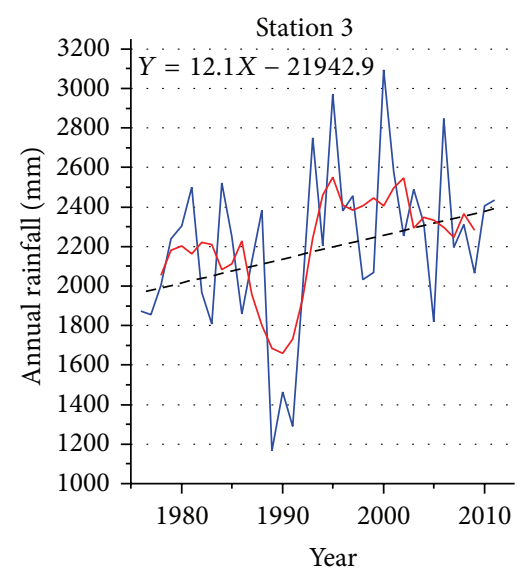

__ Annual or seasonal rainfall
- - Significant trend
$-\quad$ 5-year moving average

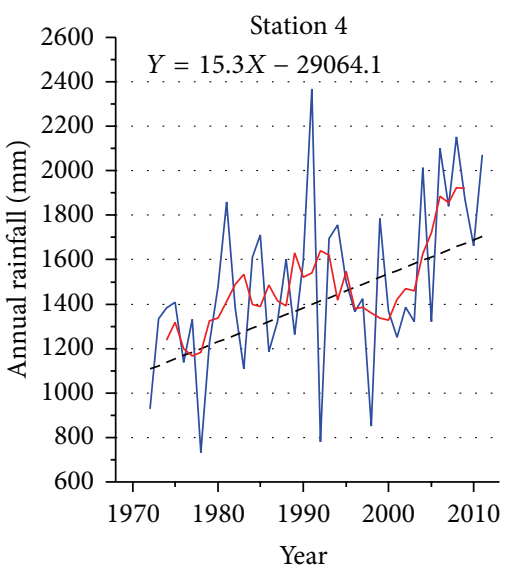

_ Annual or seasonal rainfall - - - Significant trend _ 5-year moving average

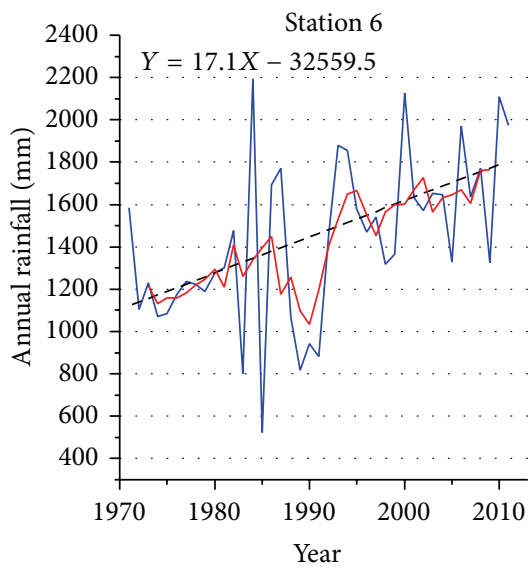

_ Annual or seasonal rainfall

- - - Significant trend

_ 5-year moving average
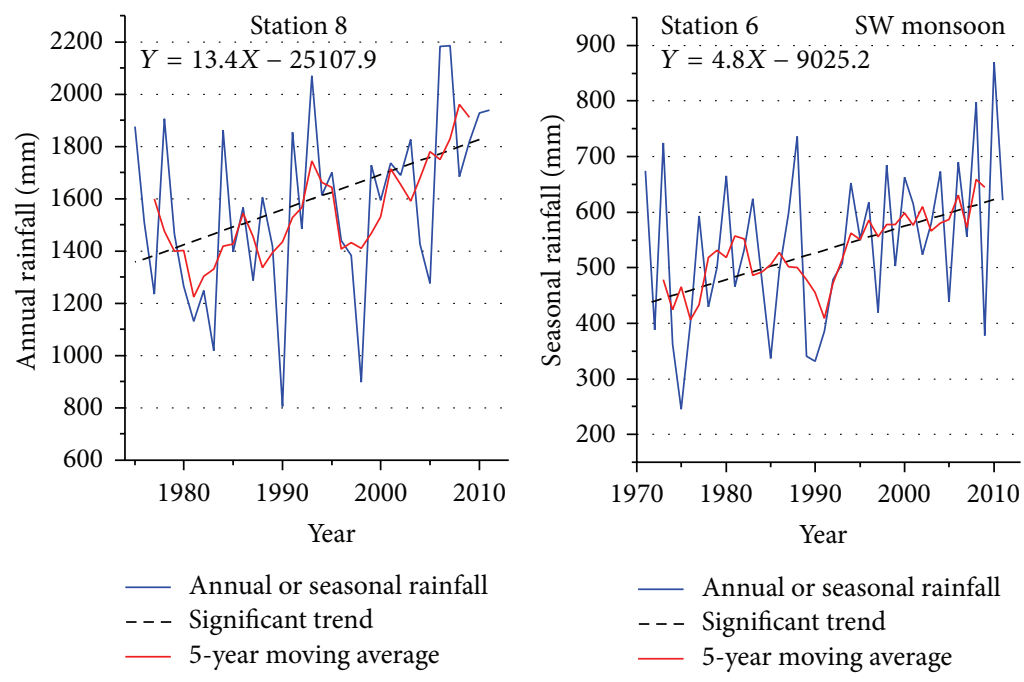

FIGURE 4: The plot of significant trends for annual and seasonal precipitation in the Langat River Basin at the 95\% confidence level.

(4) Add the monotonic trend to the prewhitened series through

$$
Y_{t}^{\prime \prime}=Y_{t}^{\prime}+\beta t
$$

where $Y_{t}^{\prime \prime}$ is the trend-free prewhitened series.

(5) Calculate the MK statistic on $Y_{t}^{\prime \prime}$ series and examine the local significance of the calculated statistics.

\section{Results and Discussion}

3.1. Analyses of Lag-1 Autocorrelation and the Prewhitening Process. The results of lag-1 autocorrelations and the prewhitening process of the annual and seasonal precipitation and temperature in the related situations are shown in Tables 3 and 4 . As shown, while the serial correlations for the annual $P, T_{\text {Min }}, T_{\text {Max }}$ before the TFPW process were all positive, positive and negative serial correlations were obtained at the seasonal time series of precipitation and temperature. While the temperature variables required the TFPW process before the MK test, the majority of the precipitation variables did not require any prewhitening procedure. The strongest and weakest autocorrelation were found in the annual $T_{\text {Min }}$ (Station 9) and SW monsoon $T_{\text {Min }}$ (Station 11), respectively. Generally, the temperature variables have a higher autocorrelation than did the precipitation variables. The majority of the seasonal precipitation time series is free of significant lag-1 serial correlation.

3.2. Trend in Precipitation and Temperature Variables. The results of the MK test, the TSS estimator, and MKRS test for $P$, $T_{\text {Max }}$, and $T_{\text {Min }}$ are presented in Tables 5, 6, and 7. The results of the MK test for the annual and seasonal time series are also presented in Figures 3 and 4.

3.2.1. Analysis of Precipitation. The results of the MK test of the annual and seasonal precipitation time series are shown in Table 5 and the significant trends at the 95\% confidence level are illustrated in Figure 4. The results of the MK test 
TABLE 3: Lag-1 serial correlation values for temperature variables before and after prewhitening.

\begin{tabular}{|c|c|c|c|c|c|c|c|c|c|c|c|c|c|}
\hline \multirow{2}{*}{ Station } & \multirow{2}{*}{$\begin{array}{c}\text { Critical } \\
r_{1}\end{array}$} & \multicolumn{2}{|c|}{$T_{\text {Max }}$} & \multicolumn{2}{|c|}{$T_{\text {Min }}$} & \multicolumn{2}{|c|}{$\mathrm{NE} T_{\mathrm{Max}}$} & \multicolumn{2}{|c|}{$\mathrm{SW} T_{\mathrm{Max}}$} & \multicolumn{2}{|c|}{$\mathrm{NE} T_{\text {Min }}$} & \multicolumn{2}{|c|}{$\mathrm{SW} T_{\text {Min }}$} \\
\hline & & $r_{1}$ & $r_{1}^{\prime}$ & $r_{1}$ & $r_{1}^{\prime}$ & $r_{1}$ & $r_{1}^{\prime}$ & $r_{1}$ & $r_{1}^{\prime}$ & $r_{1}$ & $r_{1}^{\prime}$ & $r_{1}$ & $r_{1}^{\prime}$ \\
\hline 9 & 0.37 & $0.48^{*}$ & -0.01 & $0.58^{*}$ & -0.02 & 0.36 & - & -0.03 & - & $0.55^{*}$ & -0.05 & $0.45^{*}$ & 0.34 \\
\hline 10 & 0.31 & $0.37^{*}$ & 0.08 & 0.02 & - & 0.12 & - & 0.17 & - & -0.09 & - & $0.42^{*}$ & 0.04 \\
\hline 11 & 0.30 & $0.39^{*}$ & 0.02 & $0.75^{*}$ & 0.07 & 0.15 & - & 0.16 & - & 0.16 & - & 0.02 & - \\
\hline
\end{tabular}

${ }^{*}$ Significant at the $5 \%$ significance level.

-No need to follow TFPW process.

TABLE 4: Lag-1 serial correlation values for annual and seasonal precipitation before and after TFPW process $\left(r_{1}{ }^{\prime}\right)$.

\begin{tabular}{lcccccc}
\hline Station & \multirow{2}{*}{ Critical $r_{1}$} & \multicolumn{2}{c}{$\mathrm{P}(\mathrm{mm})$} & \multicolumn{2}{c}{ NE monsoon } & \multicolumn{2}{c}{ SW monsoon } \\
\hline 1 & & $r_{1}$ & $r_{1}{ }^{\prime}$ & $r_{1}$ & $r_{1}{ }^{\prime}$ & -0.05 \\
2 & 0.31 & 0.11 & - & -0.18 & - & - \\
3 & 0.31 & 0.06 & - & -0.07 & - & -0.1 \\
4 & 0.33 & 0.27 & - & 0.06 & - & -0.03 \\
5 & 0.31 & $0.36^{*}$ & 0.05 & -0.03 & - & - \\
6 & 0.32 & 0.21 & - & -0.16 & - & - \\
7 & 0.31 & 0.29 & - & -0.13 & - & -0.23 \\
8 & 0.32 & 0.15 & - & 0.07 & - & - \\
\hline
\end{tabular}

* Significant at the $5 \%$ level of significance.

-No need to follow TFPW process.

TABLE 5: The results of the MK and TSS methods for annual and seasonal precipitation in the Langat River Basin.

\begin{tabular}{ccccccccccccc}
\hline Site & \multicolumn{4}{c}{ Annual $\mathrm{P}(\mathrm{mm})$} & \multicolumn{4}{c}{ NE monsoon } & \multicolumn{3}{c}{ SW monsoon } \\
& $S$ & $Z$ & $P$ value & $\beta(\mathrm{mm} / \mathrm{yr})$ & $S$ & $Z$ & $P$ value & $\beta(\mathrm{mm} / \mathrm{yr})$ & $S$ & $Z$ & $P$ & $\beta(\mathrm{mm} / \mathrm{yr})$ \\
\hline 1 & 110 & 1.22 & 0.22 & +4.5 & 28 & 0.30 & 0.76 & +0.8 & 104 & 1.16 & 0.24 \\
2 & 59 & 0.65 & 0.54 & +3.0 & 72 & 0.80 & 0.43 & +1.7 & -44 & -0.48 & 0.63 \\
3 & 146 & 2.03 & $0.04^{*}$ & +12.6 & 110 & 1.43 & 0.14 & +5.8 & 26 & 0.33 & 0.73 & -1.1 \\
4 & 252 & 2.92 & $0.004^{*}$ & +15.3 & 138 & 1.54 & 0.12 & +5.4 & 122 & 1.36 & 0.17 & +3.2 \\
5 & -83 & -1.0 & 0.30 & -5.8 & -37 & -0.45 & 0.65 & -1.5 & -83 & -1.03 & 0.30 & -1.6 \\
6 & 280 & 3.13 & $0.002^{*}$ & +17.1 & 136 & 1.52 & 0.13 & +4.1 & 198 & 2.21 & $0.02^{*}$ & +4.8 \\
7 & 73 & 0.91 & 0.37 & +4.5 & 43 & 0.53 & 0.59 & +0.7 & 89 & 1.11 & 0.27 & +2.5 \\
8 & 188 & 2.45 & $0.014^{*}$ & +13.4 & 91 & 1.13 & 0.26 & +3.9 & 77 & 0.96 & 0.34 & +2.2 \\
\hline
\end{tabular}

${ }^{*}$ Statistically significant at the $95 \%$ confidence level.

TABLE 6: Results of the MK and TSS methods for annual temperature variables in the Langat River Basin.

\begin{tabular}{lcccccccc}
\hline Station & & \multicolumn{3}{c}{$T_{\text {Max }}\left({ }^{\circ} \mathrm{C}\right)$} & \multicolumn{2}{c}{$T_{\text {Min }}\left({ }^{\circ} \mathrm{C}\right)$} & \\
& $S$ & $Z$ & $P$ value & $\beta\left({ }^{\circ} \mathrm{C} / \mathrm{yr}\right)$ & $S$ & $Z$ & 0.287 & +0.01 \\
\hline 9 & 145 & 3.00 & $0.003^{*}$ & +0.035 & 52 & 1.06 & $0.000^{*}$ \\
10 & 135 & 1.68 & 0.09 & +0.008 & 370 & 4.83 & +0.03 \\
11 & -29 & -0.34 & 0.75 & -0.002 & 401 & 4.84 & $0.000^{*}$ & +0.04 \\
\hline
\end{tabular}

*Statistically significant at $95 \%$ confidence level.

TABLE 7: The results of the MK and TSS methods for seasonal temperature variables in the Langat River Basin.

\begin{tabular}{cccccccccc}
\hline \multirow{2}{*}{ Station } & \multirow{2}{*}{ Variable } & \multicolumn{4}{c}{ NE Monsoon } & \multicolumn{3}{c}{ SW Monsoon } \\
& & $S$ & $Z$ & $P$ value & $\beta\left({ }^{\circ} \mathrm{C} / \mathrm{yr}\right)$ & $S$ & $Z$ & $P$ value & $\beta\left({ }^{\circ} \mathrm{C} / \mathrm{yr}\right)$ \\
\hline \multirow{2}{*}{9} & $T_{\text {Max }}$ & 117 & 2.42 & $0.015^{*}$ & +0.04 & 149 & 3.09 & $0.002^{*}$ & +0.03 \\
& $T_{\text {Min }}$ & -3 & -0.04 & 0.98 & +0.0001 & -29 & -0.62 & 0.54 & -0.007 \\
& $T_{\text {Max }}$ & 71 & 0.88 & 0.38 & +0.007 & 87 & 1.08 & 0.28 & +0.005 \\
& $T_{\text {Min }} 11$ & 411 & 5.15 & $0.000^{*}$ & +0.046 & 420 & 5.48 & $0.000^{*}$ & +0.04 \\
& $T_{\text {Max }}$ & -114 & -1.27 & 0.204 & -0.012 & 12 & 0.12 & 0.902 & +0.001 \\
& $T_{\text {Min }}$ & 558 & 6.26 & $0.000^{*}$ & +0.043 & 568 & 6.39 & $0.000^{*}$ & +0.041 \\
\hline
\end{tabular}

${ }^{*}$ Statistically significant at the $95 \%$ confidence level. 
for prewhitened annual precipitation showed that there are significant positive trends at Stations 3, 4, 6, and 8, which represents $50 \%$ of the precipitation stations. As shown in Figure 3(b), by considering the spatiality of these stations, the significance trends were obtained in these stations, which are located east and north of the basin. In addition, as illustrated by the altitude and DEM (Table 1 and Figure 1) of these stations, the positive significant trends are obtained in higher altitude areas. The land use of the area around Stations 3 and 4 are urban and forest, respectively.

The score values of this variable conformed to the $P$ values at these stations. In addition, the largest $S$ value obtained at Station 6 adapted to the most powerful significance trend test at that station. On the contrary, among these four stations with significant trends, Station 3 has the smallest $S$ value and the largest $P$ value. This indicates the smallest rate of change at this station. Nevertheless, the majority of trends for the seasonal precipitation time series were insignificant at the $95 \%$ confidence level. The only significant trend at the $95 \%$ confidence level was detected at Station 6 for SW monsoon precipitation.

The results of Theil-Sen's test of annual and seasonal precipitation time series are shown in Table 5 and significance trends at the 95\% confidence level are illustrated in Figure 4. As indicated in Table 5, the largest increasing slope of significant annual precipitation occurred at Station 6, while the smallest rates were obtained at Station 3, which were 17.1 and $12.6 \mathrm{~mm} /$ year, respectively. Based on the results of the MK test for the annual and seasonal precipitations, the test could not detect any significant negative trends in the time series.

The consequences of the MKRS test for significant annual and seasonal precipitation and temperatures are shown in Figure 5. The sequential values of the $U(t), U^{\prime}(t)$, and the confidence limits are depicted by solid red, blue, and dashed lines, respectively. As shown in Figure 5(a), the intersection point of the $U(t)$ and $U^{\prime}(t)$ curves has changed the regime of the downward trend to the increasing trend around year 1990, which became significant in the year 2002. In spite of the existence of significant positive trends at Stations 4, 6, and 8 , the MKRS test was not capable of determining the approximate beginning year of the trends. During the study period of these stations, the $U(t)$ and $U^{\prime}(t)$ have become significant, especially around the year 2000 and after.

3.2.2. Analysis of $T_{\mathrm{Max}}$. The outputs of the trend detection analysis for annual and seasonal maximum temperature in the Langat River Basin are presented in Tables 6 and 7 and also in Figures 5 and 6.

Concerning the annual and seasonal analysis of $T_{\mathrm{Max}}$, there were downward and upward trends at the stations. Three out of seven upward trends were statistically significant and none of the decreasing trends were significant at the 5\% significance level. All of the significant trends are related to Station 9, located in the mountainous area, and forest land use category. The findings also indicate that the largest $S$ value for the annual $T_{\mathrm{Max}}$ was found at Station 9. The strongest warming trend in $T_{\text {Max }}$ was conformed to the lowest $P$ value at this station. The slope estimator test indicated an increase of $3.5^{\circ} \mathrm{C}$ per century in the maximum temperature at this station, which is close to the highest rate of temperature increments, $0.99-3.44^{\circ} \mathrm{C}$, in a century, reported by the IPCC in Malaysia. The rates of significant seasonal changes in SW monsoon and $\mathrm{NE}$ monsoon seasons for $T_{\mathrm{Max}}$ were 3 and $4^{\circ} \mathrm{C}$ per century, respectively. Thus, the warming slope of $T_{\mathrm{Max}}$ in the annual period is higher than the SW monsoon season and lower than NE monsoon season. These results indicate that the monsoons' winds are active regional phenomena, which influence the observed maximum temperature during these seasons.

Regarding the annual significant trend at Station 9, the MKRS test was not able to indicate any mutation point for this powerful upward trend, as shown in Figure 5(c). The series of $U(t)$ passed the $95 \%$ confidence level in 1990, while the MKRS test detected the beginning years of trend for the annual $T_{\text {Max }}$ at Stations 10 and 11 in 1998 and 2003, respectively. However, none of these trends are significant at the $95 \%$ confidence level. As illustrated in Figure 5(e), the warming trend for the NE monsoon $T_{\mathrm{Max}}$ at Station 9 began in 1997 and became significant during the same year. The MKRS test detected other intersections between $U(t)$ and $U^{\prime}(t)$ series in the NE monsoon and SW monsoon seasons at Stations 10 and 11 after 1990, and none of them were significant at the $95 \%$ significance level.

3.2.3. Analysis of $T_{\text {Min. }}$. The trend analyses for annual and seasonal $T_{\text {Min }}$ in the three stations, Stations 9, 10, and 11, of the Langat River Basin obtained by the MK, MKRS, and TSS methods are given in Tables 6 and 7 and Figures 6 and 7 . The annual MK trend test results identified the maximum $S$ value at Station 11 and the smallest one at Station 9. Therefore, Station 9, which had the most powerful trend in $T_{\text {Max }}$, was replaced by Station 11 for $T_{\text {Min }}$. The increasing significant trend of the annual $T_{\text {Min }}$ at Stations 10 and 11 were significant at the $95 \%$ confidence level, while it was not as strong as the annual increment in $T_{\mathrm{Max}}$ at Station 9.

According to the results, the highest value of the slope for the annual minimum temperature was identified at Station 11 $\left(0.4^{\circ} \mathrm{C} /\right.$ decade $)$, while the lowest value was obtained at Station $9\left(0.1^{\circ} \mathrm{C} /\right.$ decade $)$. As shown in Table 6 , the probability of this trend being obtained randomly is close to zero, and thus the test results are significant at the $95 \%$ confidence level. The MK trend test for the SW monsoon and NW monsoon seasons indicated significant trends at Stations 10 and 11. The MK trend analysis of the seasonal $T_{\text {Min }}$ showed a strong significant increasing trend at Stations 10 and 11 in the seasonal time periods. The altitudes of Stations 10 and 11 are less than the altitude of Station 9. The rates of seasonal increasing in $T_{\text {Min }}$ at these two stations are about $4^{\circ} \mathrm{C}$ per century, which is near the NE monsoon trend in $T_{\mathrm{Max}}$ at Station 9.

The sequential MK test could not detect any beginning point for significant seasonal and annual positive trends. The result of this test showed a mutation point only at Station 9 for annual and seasonal trends in 2001 that passed the significant confidence levels in this year.

Therefore, the results of the present study indicated a climate change signal for annual rainfall, as well as the 


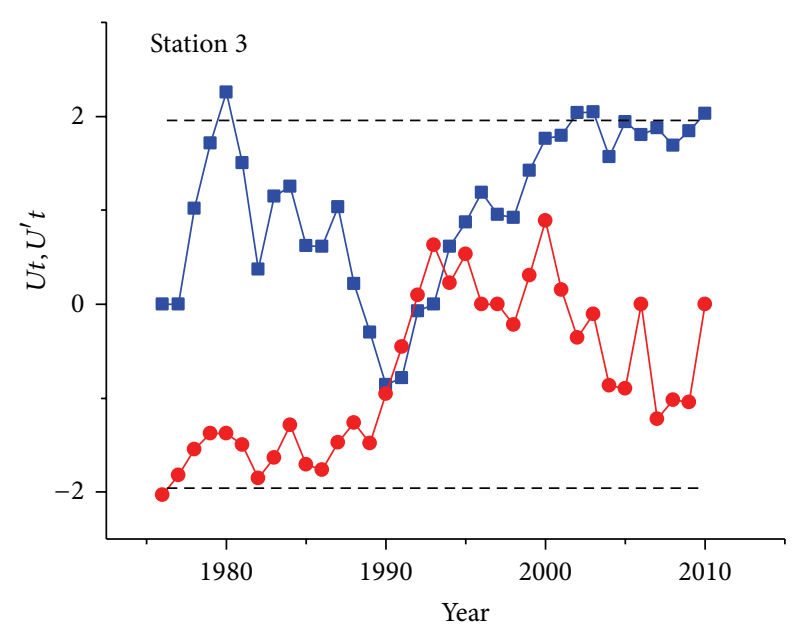

(a)

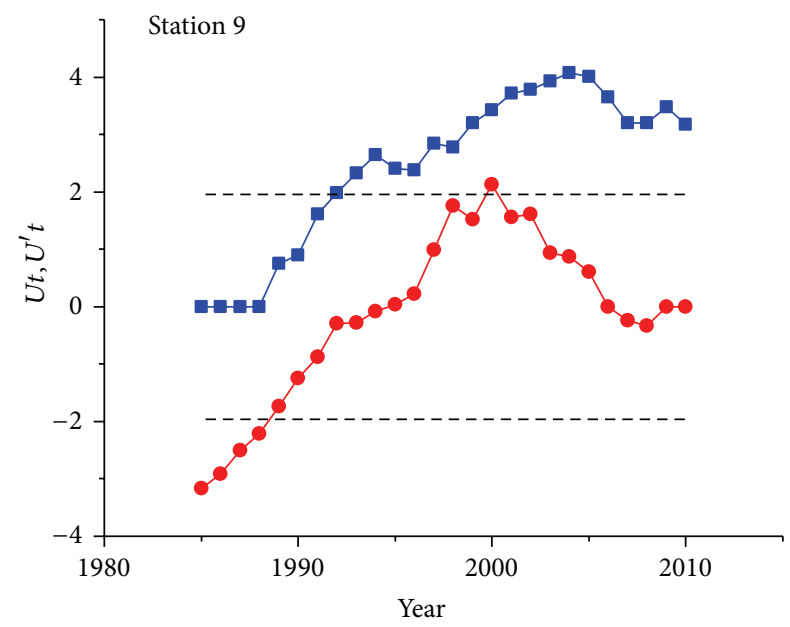

(c)

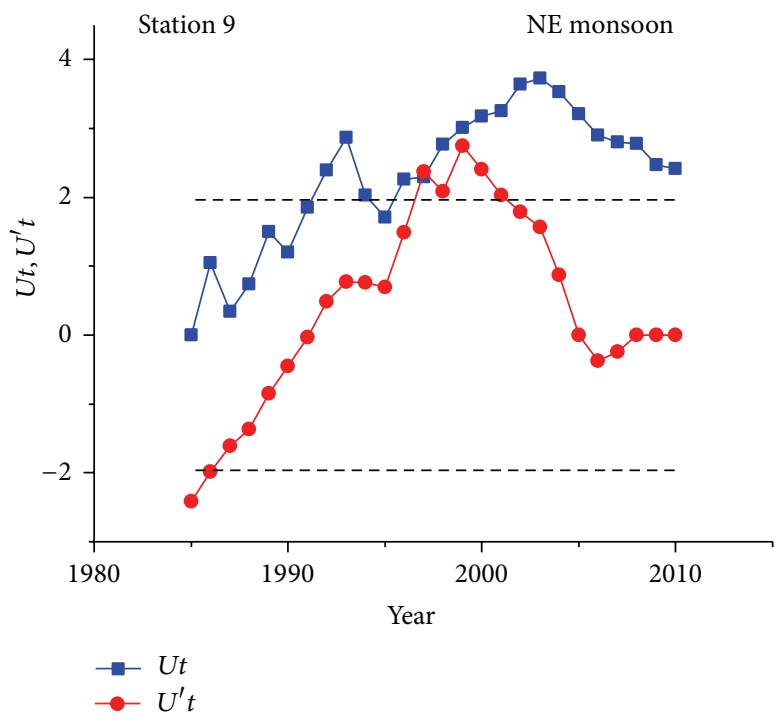

(e)

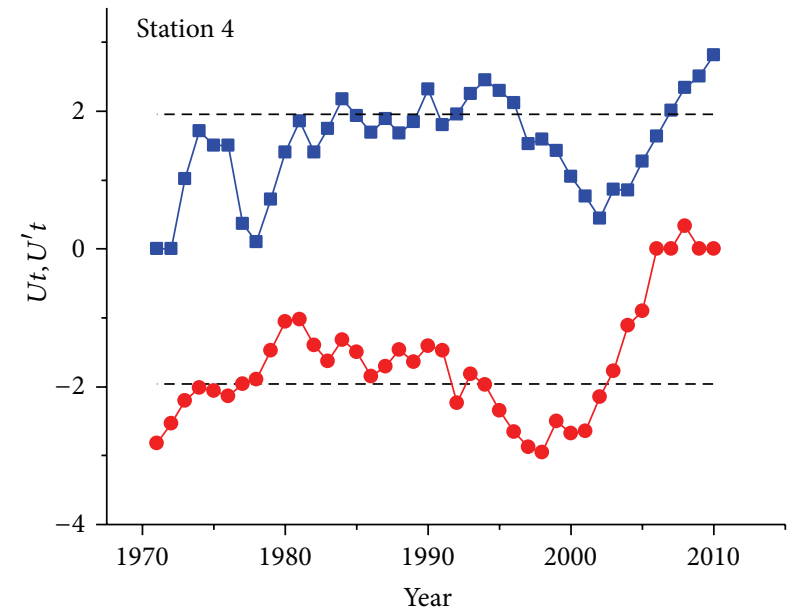

(b)

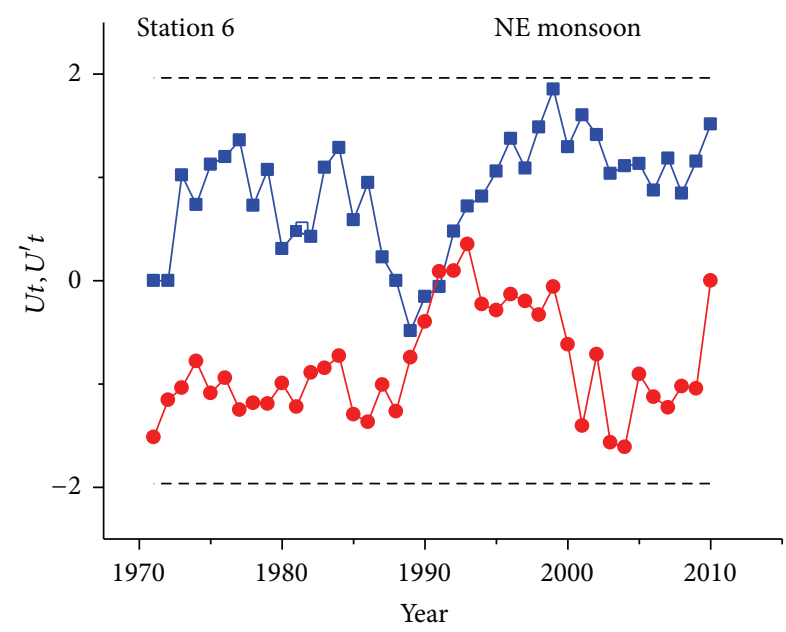

(d)

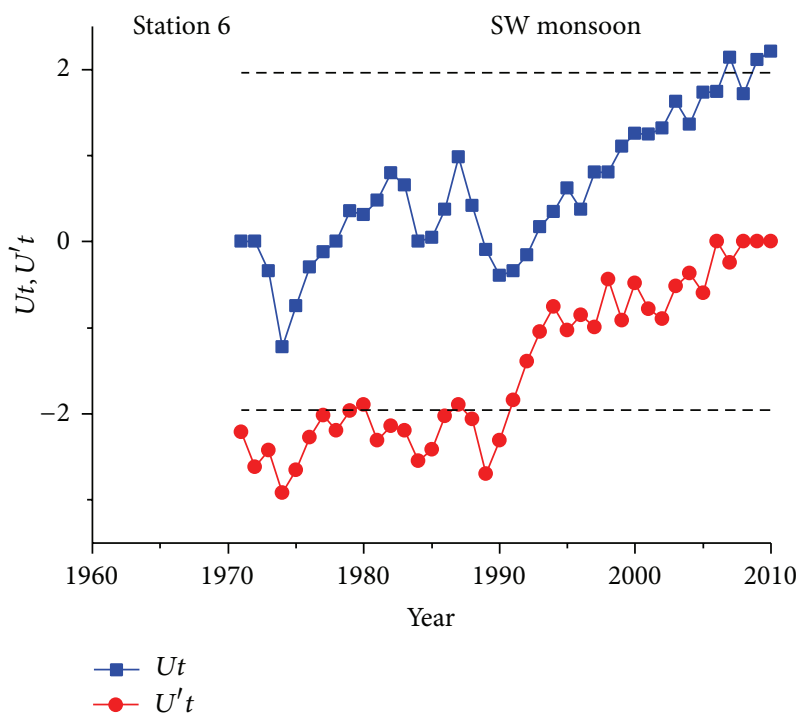

(f)

FIGURE 5: Graphical example of $U(t)$ and backward series $U^{\prime}(t)$ of the MKRS test for annual analysis ((a), (b), and (c)), NE monsoon season $((d)$, and (e)), and SW monsoon (f) for precipitation and temperature at the stations with significant trends at the $95 \%$ confidence level. 

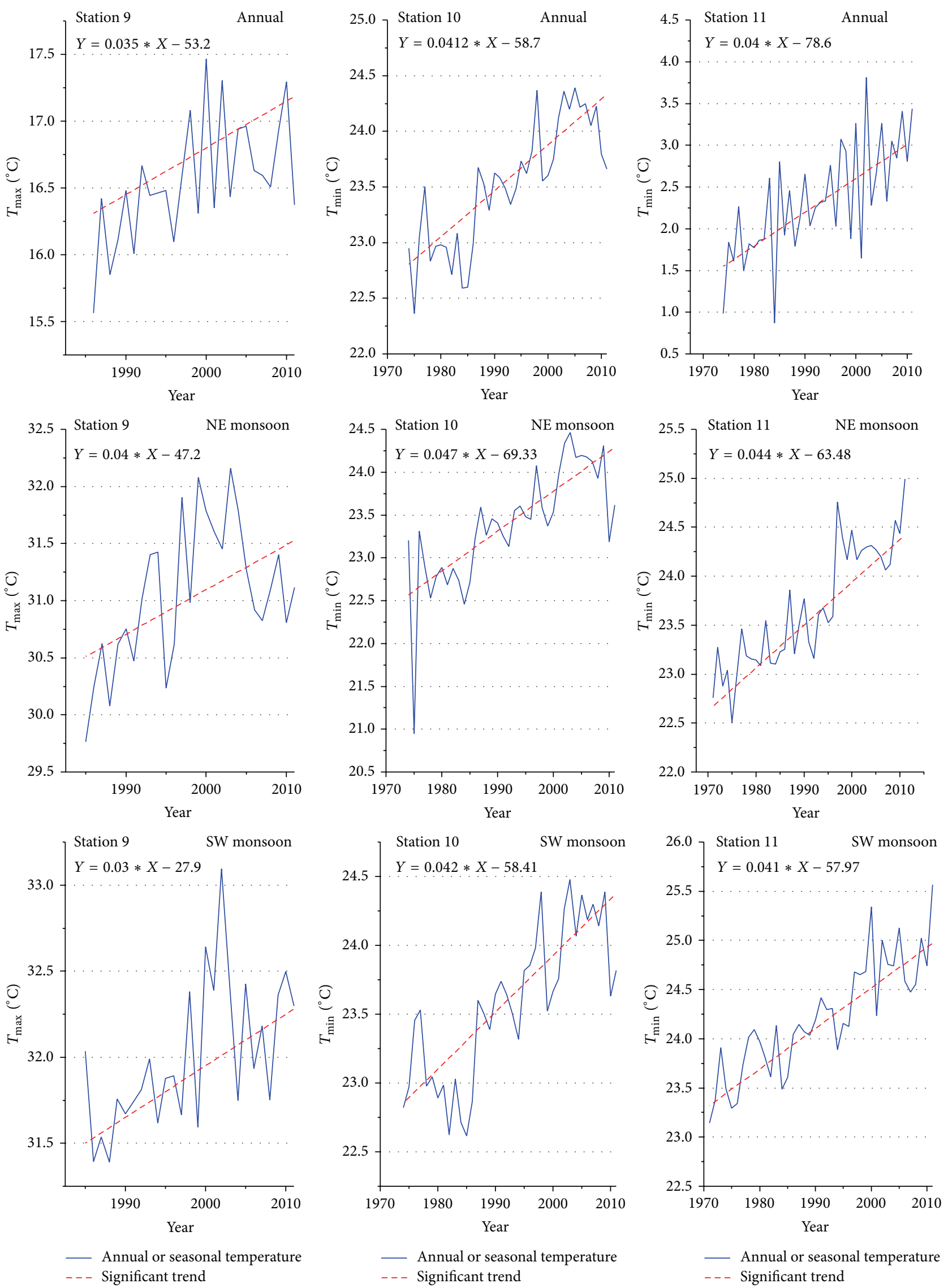

FIGURE 6: Results of significant MK trends for annual and seasonal temperature variables in the Langat River Basin at the $95 \%$ confidence level. 


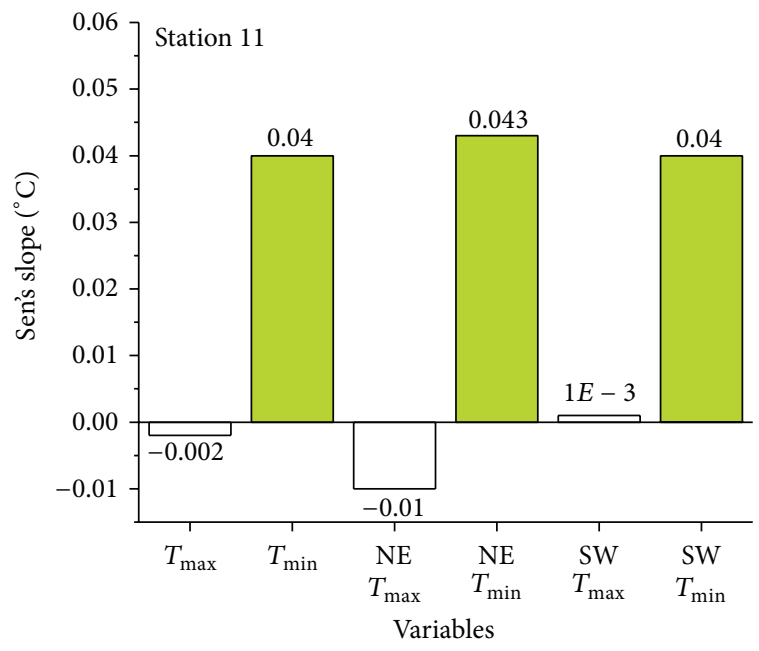

Significant trend Insignificant trend

(a)

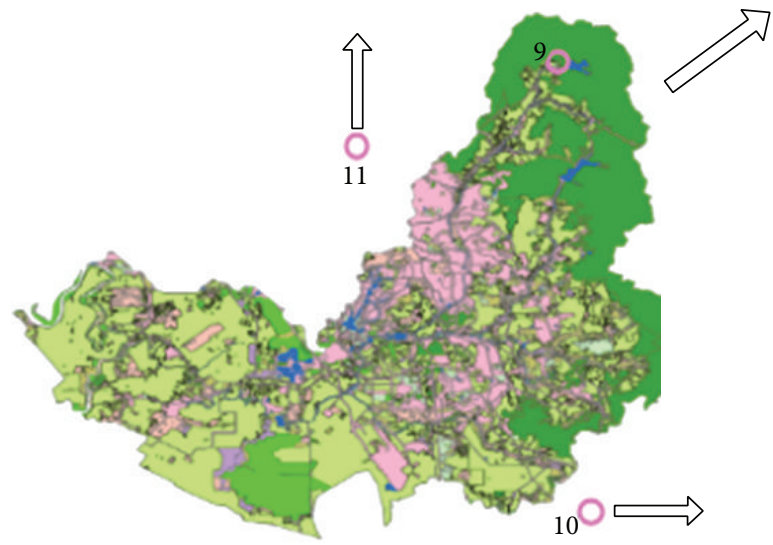

Category
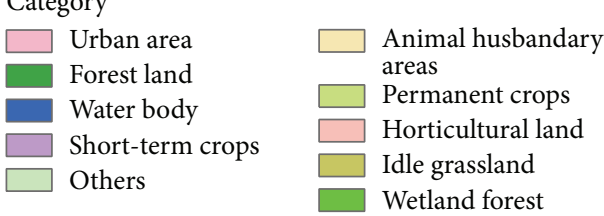

(c)

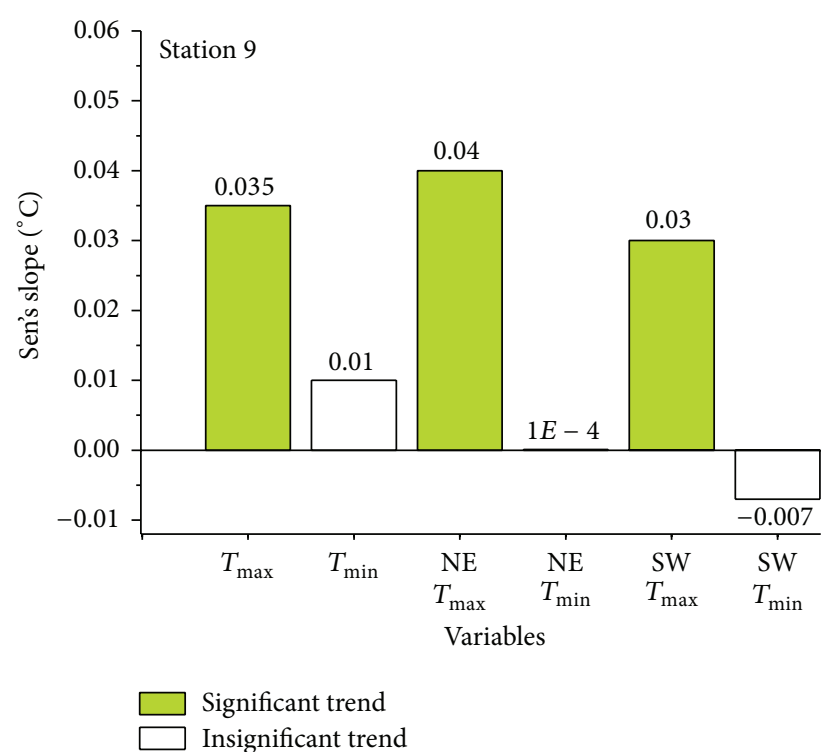

(b)

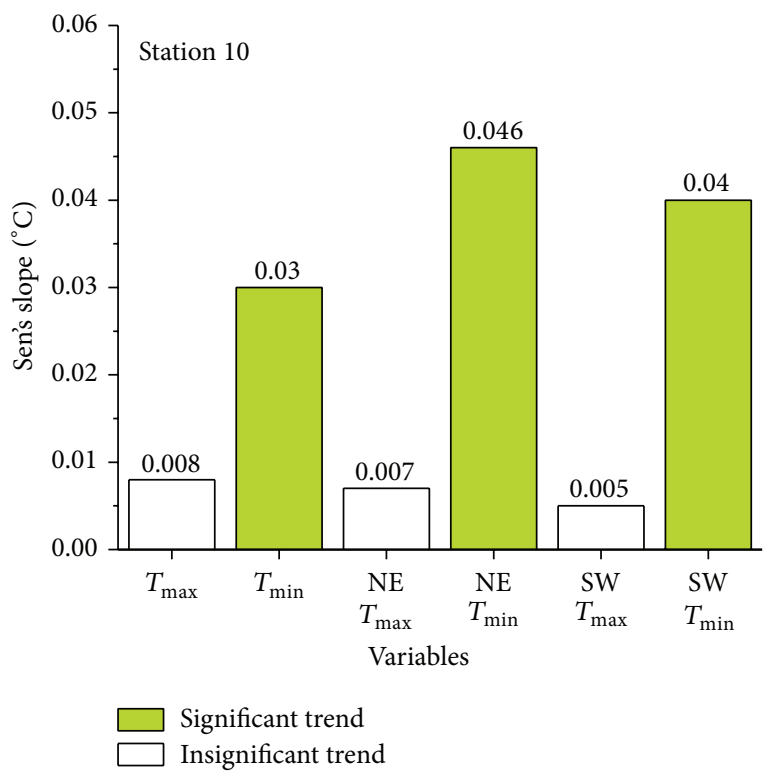

(d)

FIGURE 7: The spatial distribution of significant and insignificant trends for annual and seasonal temperatures along with corresponding Sen's slope values per year.

maximum and minimum temperatures in the Langat River Basin. These findings reflect other researchers that looked for signs of climate change for discrete climate parameters in Malaysia [10, 36, 37]. As far as we are aware, the present study is the only one that simultaneously focused on the slope of the trend in $P, T_{\mathrm{Max}}$, and $T_{\mathrm{Min}}$ besides the beginning time of change in climate parameters in the Langat River Basin.

3.3. Uncertainty in Trends. A bootstrap method was applied herein on the database to assess the uncertainty in the estimated significant slopes associated with the slope estimator method in significant trends for the annual and seasonal precipitation and maximum and minimum temperatures by using 1000 resampling times. The bootstrap histogram, box plot, confidence intervals, and other useful statistics of the bootstrapped slope values at these stations are shown in Table 8 and Figures 8 and 9. The 95\% confidence intervals of the median bootstrapped slopes were computed using the percentile method. As shown in Table 7, all of the measured Theil-Sen's slope values are placed at the 95\% confidence intervals. The box-plot figure also illustrated more nonnormality in the slopes' distribution for temperature than with the precipitation in the significant stations. 


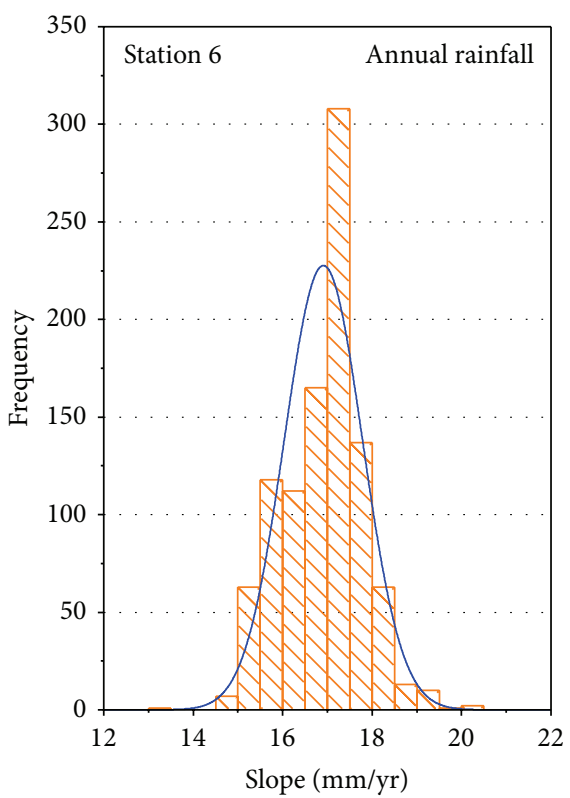

(a)

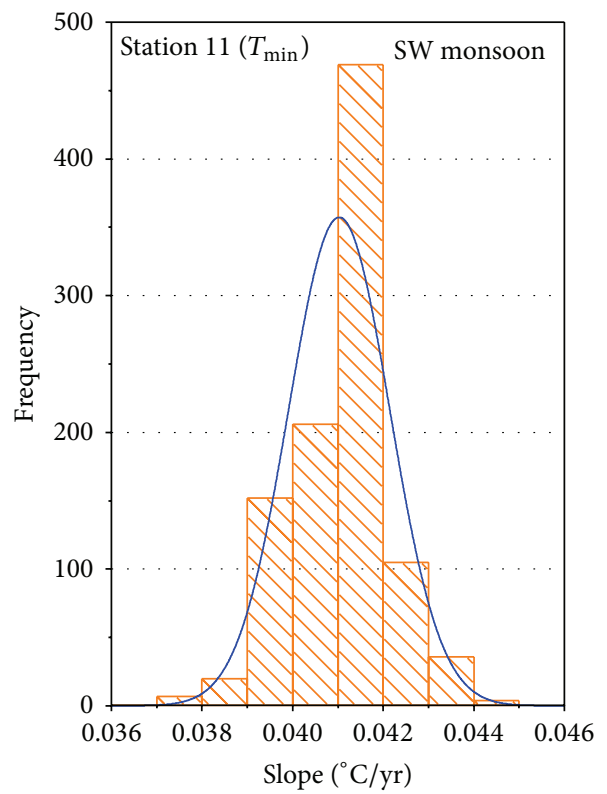

(c)

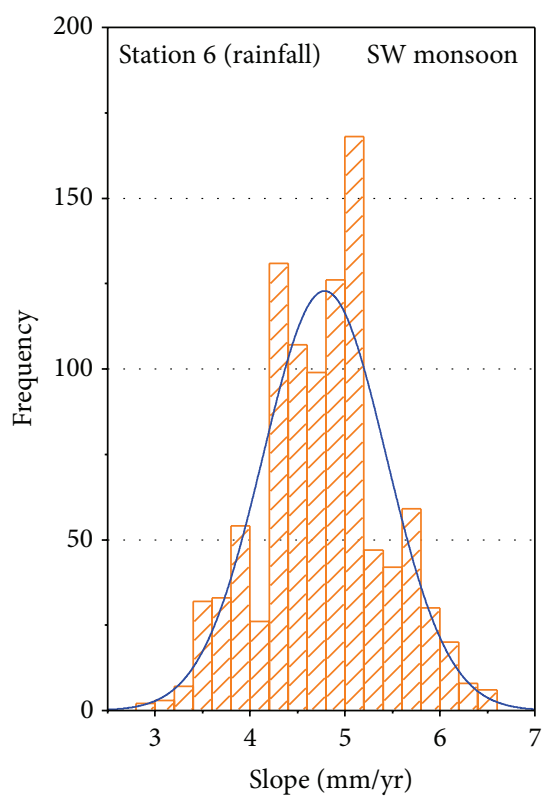

(b)

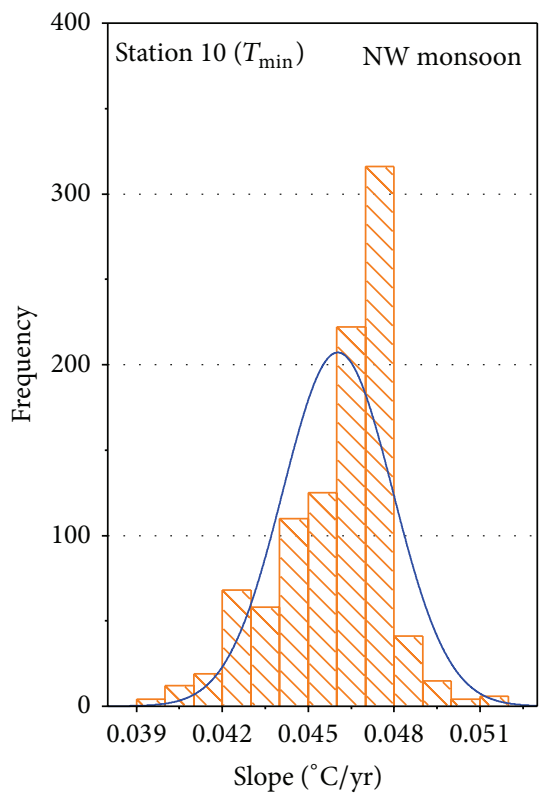

(d)

FIGURE 8: Examples of histogram of bootstrap slopes in significant trend for annual and seasonal temperatures $\left(T_{\text {Max }}, T_{\text {Min }}\right)$ and precipitation.

\section{Conclusions}

Changes in the climate variables due to global warming and regional systems, such as monsoon phenomena, were investigated at the Langat River Basin to precisely determine the rate of changes in this strategic river basin. The main objective of this study was the annual and seasonal trend analysis for $P, T_{\mathrm{Max}}$, and $T_{\mathrm{Min}}$ at the 11 selected stations in this river basin to support the water management policymakers for planning for the future. Three nonparametric methods, the MK, MKRS test, and TSS, were applied to complete the detection of trends for the variables. The analyses of the MK and TSS were performed after eliminating the influence of significant lag-1 serial correlations from the time series using the TFPW technique. The results of these trend tests showed significant increasing trends at four stations (Stations 3, 4, 6 , and 8) for annual precipitation, one station for the SW monsoon season (Station 6), one station for the seasonal and annual $T_{\text {Max }}$, and two stations for the annual and seasonal $T_{\text {Min }}$, at the $95 \%$ confidence level. The rate of changes in this river basin showed that north and east of basin have faced a moderate change in the maximum and minimum 


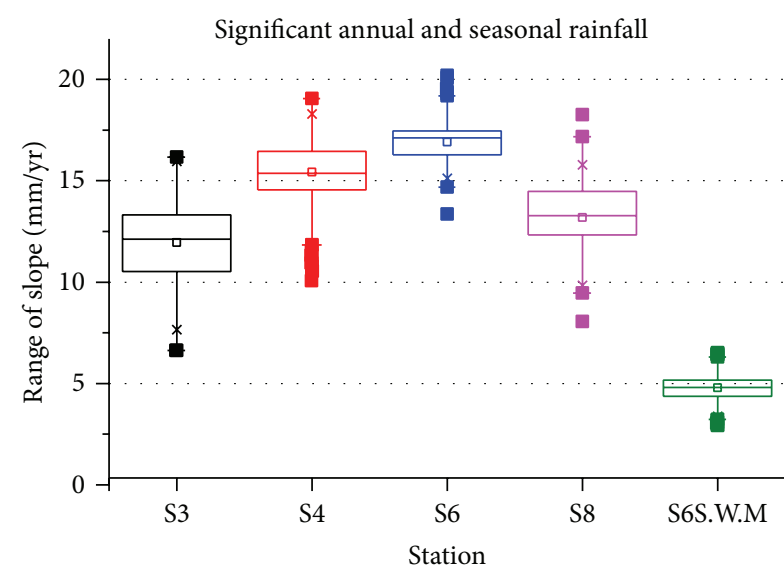

(a)

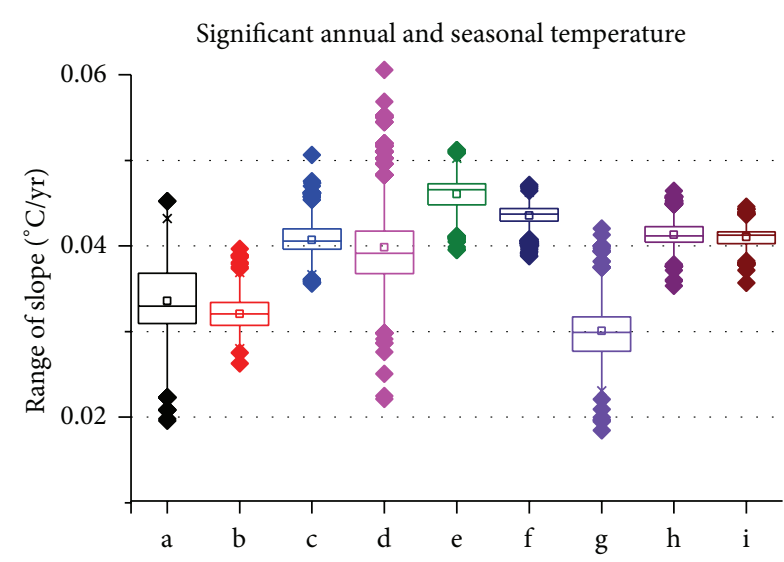

(b)

FIGURE 9: Boxplot of slope obtained from bootstrap method for the significant trends of annual and seasonal rainfall and temperatures (a: S9 $\left(T_{\text {Max }}\right)$, b: S10 $\left(T_{\text {Min }}\right)$, c: S11 ( $\left.T_{\text {Min }}\right)$, d: S9 ( $T_{\text {Max }}$ NE monsoon), e: S10 ( $T_{\text {Min }} N E$ monsoon), f: S11 ( $T_{\text {Min }} N E$ monsoon), g: $S 9$ ( $T_{\text {Max }} S W$ monsoon), h: S10 ( $T_{\text {Min }}$ SW monsoon), i: S11 ( $T_{\text {Min }}$ SW monsoon)).

TABLE 8: The bootstrap results for slopes in significant trends for rainfall and maximum and minimum temperatures in the Langat River Basin.

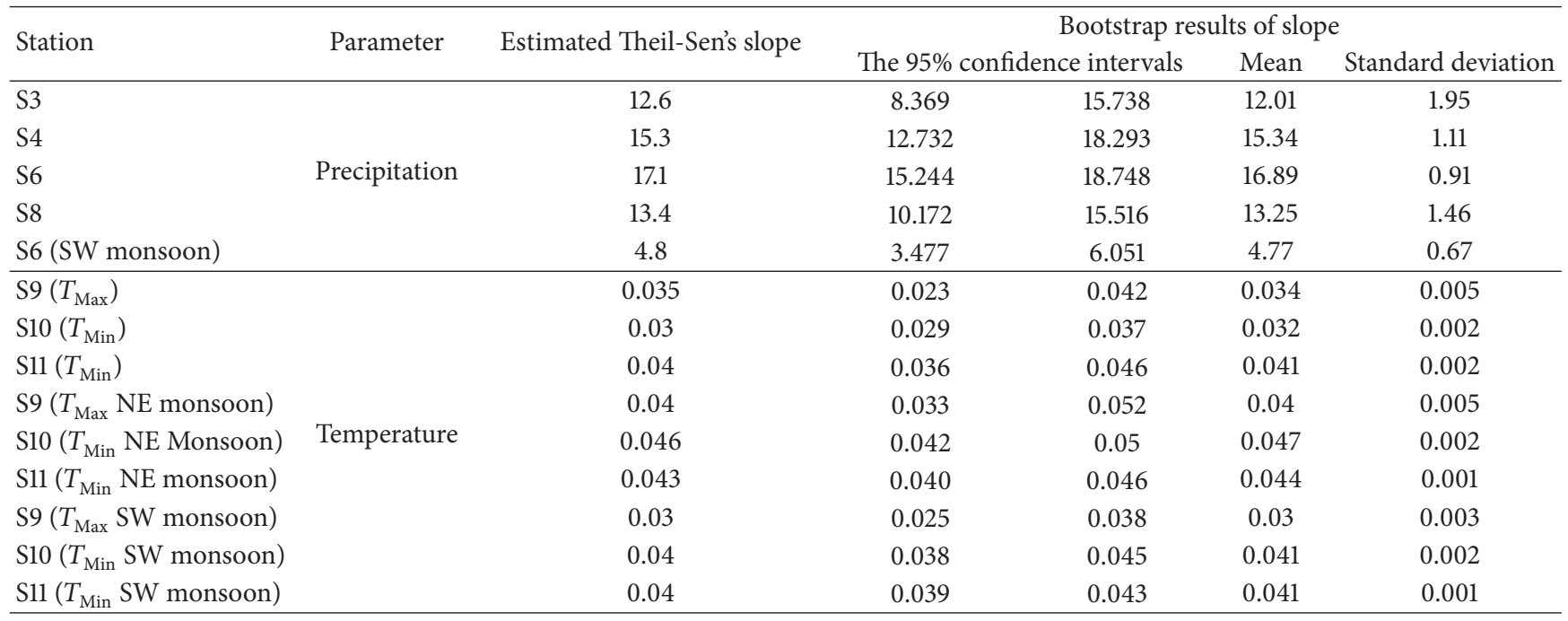

temperatures and rainfall during the past four decades. In other words, the weather north and east of basin became warmer and wetter during the study period.

While the rates of upward significant changes for annual precipitation ranged from 12.6 to $17.1 \mathrm{~mm}$ per year, for the rate of change in SW monsoon, a significant trend was found to be about one-third ( $4.8 \mathrm{~mm}$ per year). The TSS test determined the slope of an upward trend for the annual and seasonal $T_{\text {Max }}$ in a range of 3.5 to $4^{\circ} \mathrm{C}$ per century. It is the same for the annual and seasonal significant trends for the $T_{\text {Min }}$ variable. Also, all of the significant trends were found at the stations located in the north, east, and northeast parts of the basin. Their elevations are higher than those stations in the west region of the river basin. The land use of these stations is forest or urban area. The other important result is that all of the significant long-term trends in precipitation and temperature gradually increased during the study period.
Also, it showed that the monsoon system is a powerful phenomenon among all other active systems in the region. This rate of change in the annual and seasonal rainfall, $T_{\text {Max }}$ and $T_{\text {Min }}$ temperature may drive some changes in land cover/land use of the basin therefore increasing the flood frequency in this region, especially during the NE monsoon season. Furthermore, changes in the water demand pattern for all type of usage in the region is another consequence, due to the alterations in climate parameters. Future studies in trend analysis for extreme rainfall events and other indices of precipitation in the Langat River Basin would be very useful for future water resource planning.

\section{Conflict of Interests}

The authors declare that there is no conflict of interests regarding the publication of this paper. 


\section{Acknowledgments}

The authors would like to thank the Department of Irrigation and Drainage Malaysia (DID) and the Malaysian Meteorological Department (MMD), both under the Ministry of Natural Resources and Environment Malaysia (NRE), for providing data and technical support. The authors would also like to sincerely thank the Ministry of Science, Technology and Innovation (MOSTI) for the financial support.

\section{References}

[1] T. F. Stocker, D. Qin, G.-K. Plattner et al., "Climate change 2013: the physical science basis," in Intergovernmental Panel on Climate Change, Working Group I Contribution to the IPCC Fifth Assessment Report (AR5), Cambridge University Press, New York, NY, USA, 2013.

[2] IPCC2007, Climate Change 2007: The Physical Science Basis, IPCC, Geneva, Switzerland, 2007.

[3] S. Solomon, Climate Change 2007-The Physical Science Basis: Working Group I Contribution to the Fourth Assessment Report of the IPCC, vol. 4, Cambridge University Press, 2007.

[4] P. Nyeko-Ogiramoi, P. Willems, and G. Ngirane-Katashaya, "Trend and variability in observed hydrometeorological extremes in the Lake Victoria basin," Journal of Hydrology, vol. 489, pp. 56-73, 2013.

[5] D. H. Burn and M. A. H. Elnur, "Detection of hydrologic trends and variability," Journal of Hydrology, vol. 255, no. 1-4, pp. 107122, 2002.

[6] H. Tabari, B. S. Somee, and M. R. Zadeh, "Testing for long-term trends in climatic variables in Iran," Atmospheric Research, vol. 100, no. 1, pp. 132-140, 2011.

[7] M. Gocic and S. Trajkovic, "Analysis of changes in meteorological variables using Mann-Kendall and Sen's slope estimator statistical tests in Serbia," Global and Planetary Change, vol. 100, pp. 172-182, 2013.

[8] D. Liu, S. Guo, X. Chen, and Q. Shao, "Analysis of trends of annual and seasonal precipitation from 1956 to 2000 in Guangdong Province, China," Hydrological Sciences Journal, vol. 57, no. 2, pp. 358-369, 2012.

[9] S. Yue, P. Pilon, B. Phinney, and G. Cavadias, "The influence of autocorrelation on the ability to detect trend in hydrological series," Hydrological Processes, vol. 16, no. 9, pp. 1807-1829, 2002.

[10] W. N. Meng, C. Alejandro, A. Wahab, and A. Khairi, "A study of global warming in malaysia," Jurnal Teknologi F, pp. 1-10, 2005.

[11] F. T. Tangang, L. Juneng, E. Salimun, K. M. Sei, L. J. Le, and H. Muhamad, "Climate change and variability over Malaysia: gaps in science and research information," Sains Malaysiana, vol. 41, no. 11, pp. 1355-1366, 2012.

[12] J. Suhaila, S. M. Deni, W. A. N. Zawiah Zin, and A. A. Jemain, "Trends in peninsular Malaysia rainfall data during the southwest monsoon and northeast monsoon seasons: 19752004," Sains Malaysiana, vol. 39, no. 4, pp. 533-542, 2010.

[13] R. Nurmohamed and S. Naipal, "Trends and variation in monthly rainfall and temperature in suriname," in Proceedings BALWOIS Conference on Water Observation and InformationSystem for Decision Support, Ohrid, FY Republic of Macedonia, 25-29 May 2000, p. 3, 2004.

[14] J. Taubenheim, "An easy procedure for detecting a discontinuity in a digital time series," Zeitschrift für Meteorologie, vol. 39, pp. 344-347, 1989.
[15] J. Honaker, G. King, and M. Blackwell, "Amelia II: a program for missing data," Journal of Statistical Software, vol. 45, no. 7, pp. 1-47, 2011.

[16] C. Data, Guidelines on Analysis of Extremes in a Changing Climate in Support of Informed Decisions for Adaptation, 2009.

[17] R. Bremer, "Outliers in statistical data," Technometrics, vol. 37, pp. 117-118, 1995.

[18] J. F. González-Rouco, J. L. Jiménez, V. Quesada, and F. Valero, "Quality control and homogeneity of precipitation data in the southwest of Europe," Journal of Climate, vol. 14, no. 5, pp. 964978, 2001.

[19] A. C. Costa and A. Soares, "Homogenization of climate data: review and new perspectives using geostatistics," Mathematical Geosciences, vol. 41, no. 3, pp. 291-305, 2009.

[20] M. A. Kohler, "Double-mass analysis for testing the consistency of records and for making adjustments," Bulletin of the American Meteorological Society, vol. 30, pp. 188-189, 1949.

[21] S. M. Deni, J. Suhaila, W. Z. W. Zin, and A. A. Jemain, "Trends of wet spells over Peninsular Malaysia during monsoon seasons," Sains Malaysiana, vol. 38, no. 2, pp. 133-142, 2009.

[22] K. Chaouche, L. Neppel, C. Dieulin et al., "Analyses of precipitation, temperature and evapotranspiration in a French Mediterranean region in the context of climate change," Comptes Rendus: Geoscience, vol. 342, no. 3, pp. 234-243, 2010.

[23] D. Machiwal and M. K. Jha, "Time series analysis of hydrologic data for water resources planning and management: a review," Journal of Hydrology and Hydromechanics, vol. 54, pp. 237-257, 2009.

[24] H. Verworn, S. Krämer, M. Becker, and A. Pfister, "The impact of climate change on rainfall runoff statistics in the EmscherLippe region," in Proceedings of the 11th International Conference on Urban Drainage, pp. 1-10, Edinburgh, UK, 2008.

[25] X. Yang, L. Xu, K. Liu, C. Li, J. Hu, and X. Xia, "Trends in temperature and precipitation in the zhangweinan river basin during the last 53 years," Procedia Environmental Sciences, vol. 13, pp. 1966-1974, 2012.

[26] O. E. Scarpati, L. B. Spescha, J. A. F. Lay, and A. D. Capriolo, "Soil water surplus in salado river basin and its variability during the last forty years (buenos aires province, argentina)," Water, vol. 3, pp. 132-145, 2011.

[27] R. Sneyers, On the Statistical Analysis of Series of Observations, WMO, 1991.

[28] T. Partal and E. Kahya, "Trend analysis in Turkish precipitation data," Hydrological Processes, vol. 20, no. 9, pp. 2011-2026, 2006.

[29] H. Theil, "A rank-invariant method of linear and polynomial regression analysis," in Henri Theil's Contributions to Economics and Econometrics, pp. 345-381, Springer, 1992.

[30] Y. Dinpashoh, D. Jhajharia, A. Fakheri-Fard, V. P. Singh, and E. Kahya, "Trends in reference crop evapotranspiration over Iran," Journal of Hydrology, vol. 399, no. 3-4, pp. 422-433, 2011.

[31] D. Karpouzos, S. Kavalieratou, and C. Babajimopoulos, "Trend analysis of precipitation data in Pieria region (Greece)," European Water, vol. 30, pp. 31-40, 2010.

[32] C. J. Martinez, J. J. Maleski, and M. F. Miller, "Trends in precipitation and temperature in Florida, USA," Journal of Hydrology, vol. 452-453, pp. 259-281, 2012.

[33] M. Santos and M. Fragoso, "Precipitation variability in Northern Portugal: data homogeneity assessment and trends in extreme precipitation indices," Atmospheric Research, vol. 131, pp. 34-45, 2013. 
[34] H. von Storch and A. Navarra, Analysis of Climate Variability: Applications of Statistical Techniques, Springer, 1999.

[35] D. H. Burn, J. M. Cunderlik, and A. Pietroniro, "Hydrological trends and variability in the Liard River basin," Hydrological Sciences Journal, vol. 49, no. 1, pp. 53-68, 2004.

[36] T. Stocker, D. Qin, G. Plattner et al., Summary for Policymakers, Cambridge University Press, New York, NY, USA, 2013.

[37] N. Palizdan, Y. Falamarzi, Y. F. Huang, T. S. Lee, and A. H. Ghazali, "Regional precipitation trend analysis at the Langat River Basin, Selangor, Malaysia," vol. 117, no. 3-4, pp. 589-606, 2014. 

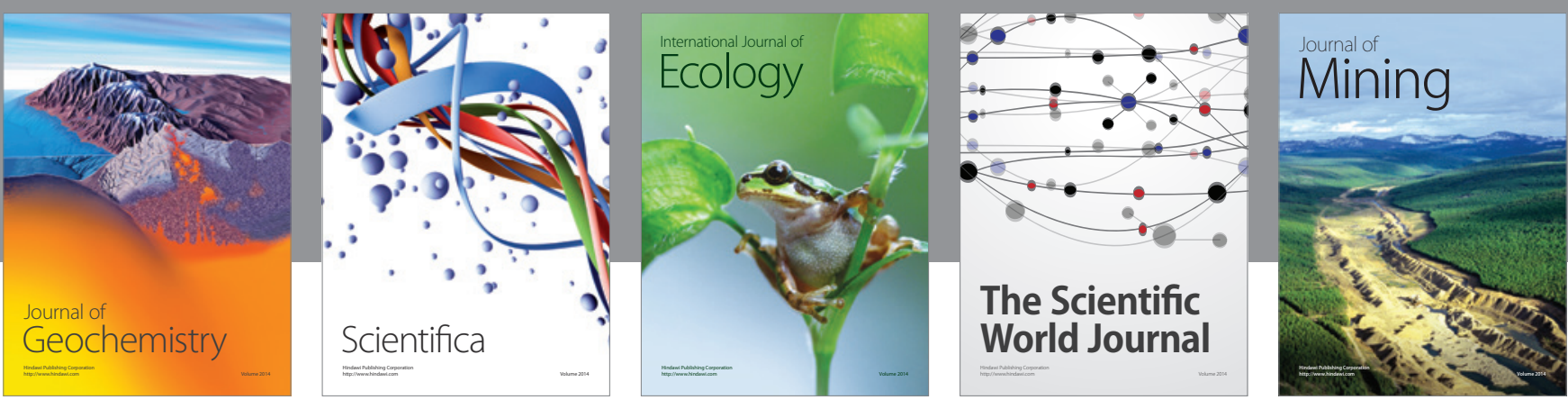

The Scientific World Journal
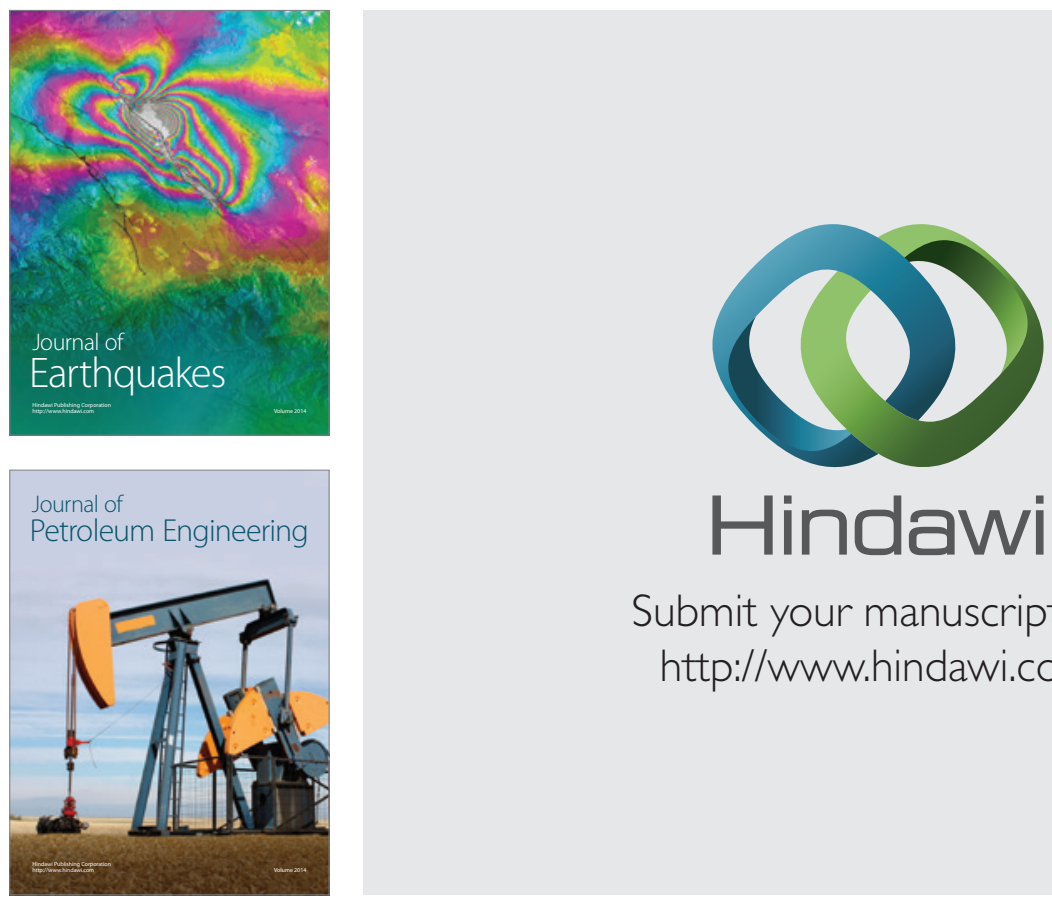

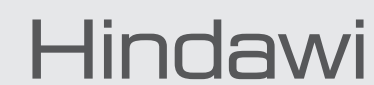

Submit your manuscripts at

http://www.hindawi.com
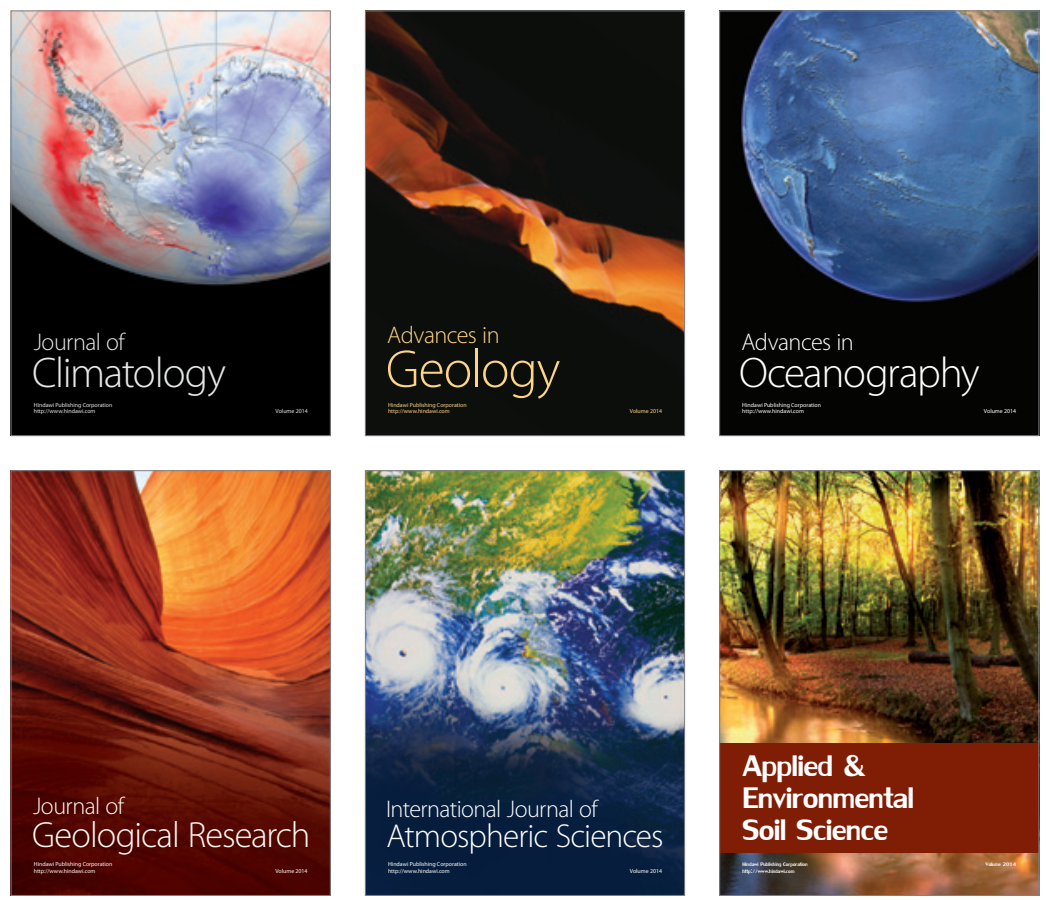
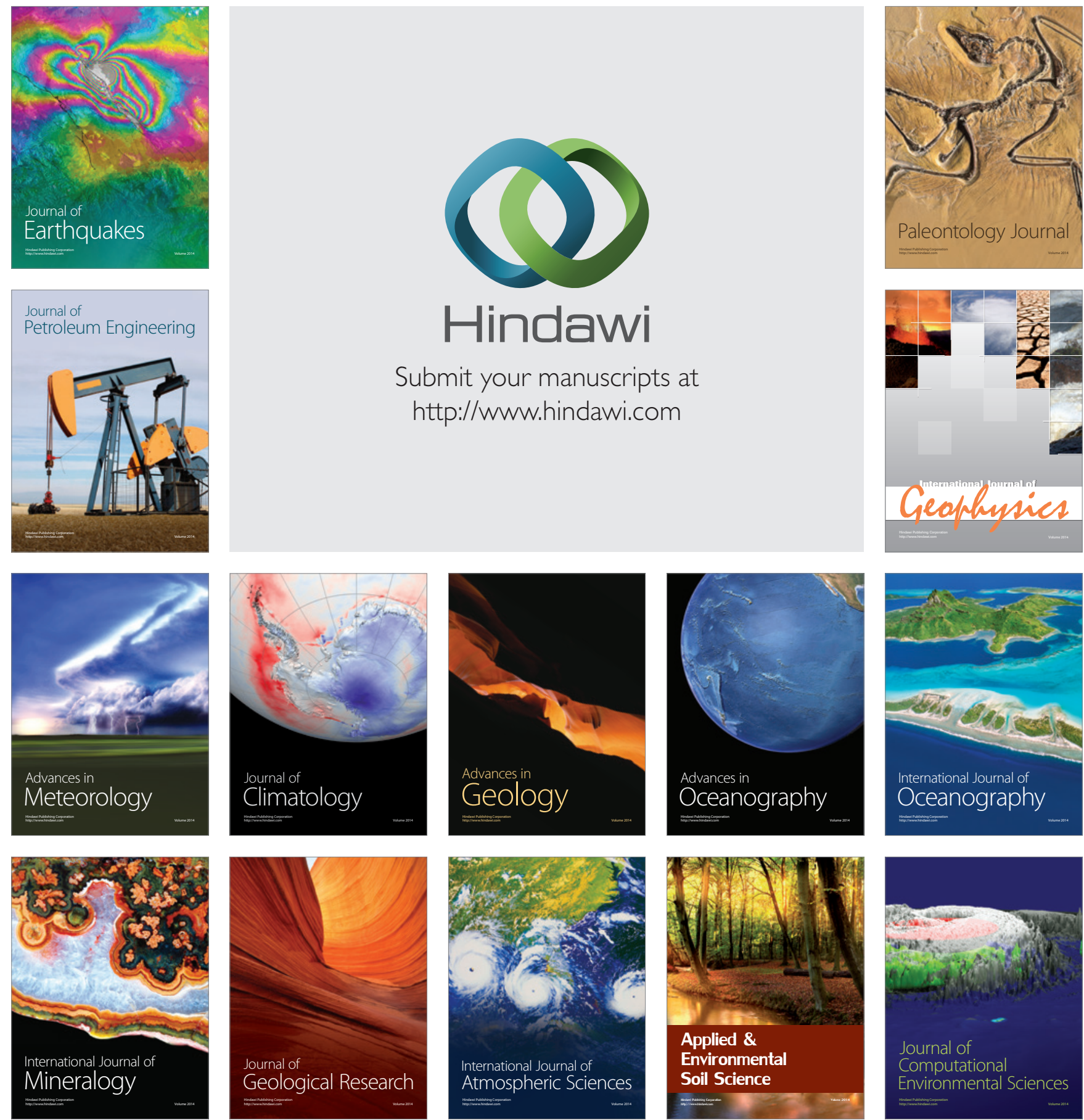